\title{
REVIEW AND ASSESSMENT OF THE POTENTIAL OF POST-IR IRSL DATING METHODS TO CIRCUMVENT THE PROBLEM OF ANOMALOUS FADING IN FELDSPAR LUMINESCENCE
}

\author{
BO LI ${ }^{1}$, ZENOBIA JACOBS $^{1}$, RICHARD G. ROBERTS ${ }^{1}$ and SHENG-HUA LI ${ }^{\mathbf{2}}$ \\ ${ }^{l}$ Centre for Archaeological Science, School of Earth and Environmental Sciences, University of Wollongong, \\ Wollongong, NSW 2522, Australia \\ ${ }^{2}$ Department of Earth Sciences, The University of Hong Kong, Pokfulam Road, Hong Kong, China
}

Received 30 January 2013

Accepted 10 April 2014

\begin{abstract}
Quartz has been the main mineral used for optically stimulated luminescence (OSL) dating of sediments over the last decade. The quartz OSL signal, however, has been shown to saturate at relatively low doses of $\sim 200-400 \mathrm{~Gy}$, making it difficult to be used for dating beyond about 200 thousand years (ka), unless the environmental dose rate is low. The infrared stimulated luminescence (IRSL) from feldspars has been shown to continue to grow to higher dose levels than quartz OSL. The application of IRSL dating of feldspars, however, has long been hampered by the anomalous fading effect. Recent progress in understanding anomalous fading of the infrared stimulated luminescence (IRSL) signals in potassium-feldspar has led to the development of post-IR IRSL (pIRIR) protocols and also a multiple elevated temperature (MET) stimulation (MET-pIRIR) protocol. These procedures have raised the prospect of isolating a non-fading IRSL component for dating Quaternary deposits containing feldspars. In this study, we review the recent progress made on (1) overcoming anomalous fading of feldspar, and (2) the development of pIRIR dating techniques for feldspar. The potential and problems associated with these methods are discussed.
\end{abstract}

Keywords: K-feldspar, infrared stimulated luminescence, post-IR IRSL, MET-pIRIR.

\section{INTRODUCTION}

Quartz has been the main mineral used for optical dating of sediment over the last decade since the development of the single aliquot regenerative-dose (SAR) protocol (Galbraith et al., 1999; Roberts et al., 1999; Murray and Wintle, 2000). The fast component of the OSL signal in quartz has been used for dating as it is rapidly bleached (Wintle and Murray, 2006), but has been shown to saturate at relatively low doses of $\sim 200$ to $400 \mathrm{~Gy}$. This has restricted its use for dating of sediments younger than

Corresponding author: B. Li

e-mail: bli@uow.edu.au about 200 thousand years $(\mathrm{ka})$, unless the environmental dose rate is low (e.g., $<1 \mathrm{~Gy} / \mathrm{ka}$ ).

Feldspars can also be used for optical dating, either using visible wavelengths for stimulation or using infrared (IR) stimulation to produce an IR stimulated luminescence (IRSL) signal (Hütt et al., 1988). Compared to quartz, feldspars have several advantages in optical dating (e.g., Aitken, 1998; Huntley and Lamothe, 2001). First, the IRSL signal from feldspar usually saturates at much higher dose levels compared to quartz OSL; this is advantageous in the context of extending the dating range of optical dating for sedimentary deposits. Second, the IRSL signal is usually inherently brighter than the quartz 
OSL signal. This enables higher precision luminescence measurements to be made, generally leading to better reproducibility of the natural and laboratory-dose measurements (Li et al., 2007b). Third, in the case of sandsized grains of alkali feldspars (K-feldspars), the high contribution to the internal dose rate from ${ }^{40} \mathrm{~K}$ and ${ }^{87} \mathrm{Rb}$ within the crystal lattice creates more luminescence, resulting in increased precision of the measured equivalent dose $\left(D_{\mathrm{e}}\right)$ for young samples. This higher internal dose rate also reduces the effect that inhomogeneity in the beta and gamma-dose rate spheres and water content can have on the total dose rate, resulting in improved precision. Furthermore, an isochron dating method utilising the internal dose rate of $\mathrm{K}$-feldspars can also be used to overcome changes in the environmental dose rate $(\mathrm{Li}$ et al., 2007a; Li et al., 2008a; Li et al., 2008b). Despite all these advantages, feldspars have long been known to exhibit a phenomenon called anomalous fading (Wintle, 1973; Spooner, 1992, 1994; Huntley and Lamothe, 2001; Huntley and Lian, 2006). Anomalous fading relates to the leakage of electrons from traps that give rise to IRSL at a much faster rate than would be expected from kinetic considerations. This phenomenon has hampered the application of luminescence dating of feldspar extracted from sediment for many years.

Recent progress in understanding anomalous fading of feldspar has raised the prospect of isolating a nonfading IRSL component for dating Quaternary deposits containing feldspars. By first bleaching feldspar grains using IR photons at $50^{\circ} \mathrm{C}$ and then measuring the post-IR IRSL (pIRIR) signal at an elevated temperature $\left(>200^{\circ} \mathrm{C}\right)$, it is possible to preferentially sample the electrons from the traps that suffer least from fading (Thomsen et al., 2008). Since the initial observation, different pIRIR procedures have been developed, including a two-step (e.g., Thomsen et al., 2008; Buylaert et al., 2009; Thiel et al., 2011a) and a multiple elevated temperature (MET) post-IR IR stimulation procedure $(\mathrm{Li}$ and $\mathrm{Li}$, 2011a; 2012a).

In this paper, we summarise the results from over 300 samples presented in recently published studies using different pIRIR signals (Table S1). We focused on various luminescence behaviours and the performance of the SAR procedure when measuring the pIRIR signals, and we also discuss the potential and problems of using the pIRIR signals for dating sediments.

\section{ANOMALOUS FADING}

Anomalous fading was first observed for volcanic feldspars measuring their thermoluminescence (TL) signals (Wintle, 1973). It was subsequently also reported for IRSL signals from a wide range of feldspars extracted from sediments (Spooner, 1994; Huntley and Lamothe, 2001; Huntley and Lian, 2006). Anomalous fading has been suggested to be the main reason for underestimation of $D_{\mathrm{e}}$ when IRSL measurements are made shortly after irradiation (Spooner, 1994; Huntley and Lamothe, 2001).

Anomalous fading in feldspars has been explained as a result of tunnelling recombination between electronhole pairs (e.g., Aitken, 1985; Visocekas, 1985; Visocekas et al., 1994). This explanation is strongly supported by the observation of phosphorescence when recently irradiated samples were cooled down to liquid nitrogen temperatures (Visocekas, 1985). The extent of anomalous fading can be quantified using a laboratory fading test, which involves measuring the signal decay after irradiation and different delay periods (Huntley and Lamothe, 2001; Auclair et al., 2003). Decay of the IRSL signal as a function of storage time appears to follow a power law with linear decay on a log (time) scale, which enables the calculation of a fading rate (g-value) expressed as percentage loss per decade, where a decade is a factor of 10 in time since laboratory irradiation (Aitken, 1985). Huntley and Lamothe (2001) demonstrated that anomalous fading was ubiquitous across Canada regardless of geological origin and this was later confirmed by Huntley and Lian (2006) who measured g-values of 3-7\% per decade for most of the 77 samples of $\mathrm{K}$-feldspar that they extracted from sediments around the world. These findings suggested that anomalous fading is a universal phenomenon for feldspars.

Given the great potential for extending the age range of luminescence dating using feldspar, a number of attempts have been made over the last two decades or so to avoid anomalous fading (e.g., Sanderson and Clark, 1994; Lamothe and Auclair, 1999; Huntley and Lamothe, 2001; Zhao and Li, 2002; Lamothe et al., 2003; Tsukamoto et al., 2006; Li et al., 2008b). One such attempt was the storage of mineral grains such as zircon at elevated temperatures before measurement of the TL signal, which Templer (1985) found removed anomalous fading. Spooner (1992), however, later reported that the fading for a labradorite was unchanged regardless of whether the sample was stored at 10 or $100^{\circ} \mathrm{C}$. Another method proposed by Sanderson and Clark (1994) used time-resolved signals. They suggested that different parts of the pulsed OSL signal of feldspar have different fading rates, and anomalous fading might be avoided by selecting those parts of the signal that do not fade. A similar conclusion was reached by Tsukamoto et al. (2006) and Jain and Ankjærgaard (2011). In a later study, Li et al. (2008b) proposed an isochron IRSL dating method, which uses the IRSL signal from K-feldspar grains of different grain sizes. This method appears to avoid the problem of anomalous fading ( $\mathrm{Li}$ et al., 2007a; $\mathrm{Li}$ et al., 2008a; Li et al., 2008b). They suggested that the internal dose is responsible for generating a non-fading signal, but the underlying mechanism remains controversial (Huntley, 2011; Li et al., 2011) and the application of this method is restricted to aeolian samples with homogeneous grain-to-grain luminescence characteristics. 
Several methods have also been developed to correct for anomalous fading. Lamothe and Auclair (1999) proposed 'the fadia method' using single-grain IRSL measurements. This involves calculation of a ratio $\left(R_{\mathrm{I}}(t)\right)$ of the luminescence measured after a laboratory irradiation compared to that measured before irradiation (Lamothe and Auclair, 1997). By comparing the values $R_{\mathrm{I}}$ measured at different delay times $\left(R_{\mathrm{I}}\left(t_{1}\right)\right.$ and $\left.R_{\mathrm{I}}\left(t_{2}\right)\right)$, a value of $R_{\mathrm{I}}$ representing no fading can be obtained by extrapolation. This $R_{\mathrm{I}}$ value is then used to correct the growth curve to obtain a corrected age. Huntley and Lamothe (2001) also proposed a method to correct for anomalous fading, based on the measurement of the gvalue. This correction method was later simplified by Lamothe et al. (2003) by incorporating the environmental and laboratory dose rates into the equation. A major drawback of these correction methods are that their application is restricted to relatively young sediments (e.g., younger than $\sim 20-50 \mathrm{ka}$ or $100 \mathrm{ka}$ in low dose rate environments) with linear dose-response curves. For older samples, such methods also become unreliable due to the dependency of the anomalous fading rate on the size of the natural dose received (Kars et al., 2008; Li and Li, 2008; Morthekai et al., 2008). It would thus appear that most of these methods are more or less model- or sampledependent, which limits standard application of feldspar IRSL dating similar to what we have become accustomed to for quartz OSL dating. Targeting a non-fading signal, therefore, appears to be the best way forward so that anomalous fading can be avoided all together.

\section{IDENTIFICATION OF A NON-FADING SIGNAL}

\section{Two-step post-IR IRSL}

Although Wintle (1973) reported anomalous fading of thermoluminescence (TL) in feldspars, Valladas and Valladas (1979) and other subsequent studies (e.g., Guérin and Valladas, 1980) found that the high temperature TL of plagioclase feldspars is not affected by fading. Jain and Singhvi (2001) made similar observations for the optical signal when they observed that IR bleaching of feldspars at $220^{\circ} \mathrm{C}$ resulted in a remnant population of more thermally stable traps that could potentially be probed by high temperature IR stimulation. Following this suggestion, Thomsen et al. (2008) found that IR signals stimulated at $225^{\circ} \mathrm{C}$ faded much less than those stimulated at $50^{\circ} \mathrm{C}$ and that the later part of the IRSL signal exhibits a lower fading rate compared to its initial part. They suggested that the IRSL signal observed at a low stimulation temperature (e.g., $50^{\circ} \mathrm{C}$ ) is mainly the result of tunnelling between spatially close donoracceptor pairs, while the signal observed at higher stimulation temperatures is the result of tunnelling between spatially distant donor-acceptor pairs or thermallyassisted hopping among band-tail states. Since anomalous fading is a result of tunnelling between spatially close donor-acceptor pairs, they expected that prolonged expo- sure to IR at a low stimulation temperature should deplete the spatially close (or easy-to-fade) donor-acceptor pairs and lead to a reduction in the fading component. This led to the development of a two-step post-IR IRSL dating method (Thomsen et al., 2008) in which an IR stimulation at a lower temperature (T1) is applied before measurement of the IRSL signal at a higher temperature (T2) (Table 1). Since then, different versions of the pIRIR method, using different combinations of IR stimulation temperatures (T1 and T2), have been proposed. Here we will use the term 'pIRIR(T1, T2)' to refer to the temperatures used in the different two-step pIRIR procedures.

Thomsen et al. (2008) first tested the anomalous fading rate of the pIRIR signal measured at $225^{\circ} \mathrm{C}$ after an initial IRSL measurement at $50^{\circ} \mathrm{C}(\operatorname{pIRIR}(50,225))$ and a preheat of $250^{\circ} \mathrm{C}$ for $60 \mathrm{~s}$. They found that the laboratory

Table 1. The two-step pIRIR and multi-elevated-temperature pIRIR (MET-pIRIR) protocols.

\begin{tabular}{|c|c|c|}
\hline \multicolumn{3}{|c|}{ Post-IR IRSL protocols } \\
\hline Step & Treatment & Observed \\
\hline \multicolumn{3}{|c|}{ Two-step pIRIR protocol } \\
\hline 1 & Give regenerative dose, $D_{i}^{\mathrm{a}}$ & \\
\hline 2 & Preheat at 250 or $320^{\circ} \mathrm{C}$ for $60 \mathrm{~s}^{b}$ & \\
\hline 3 & IRSL measurement at T1 for $200 \mathrm{~s}$ & $\mathrm{Lx}_{\mathrm{x}(50)}$ \\
\hline 4 & IRSL measurement at T2 for $200 \mathrm{~s}$ & $L_{x(T)}$ \\
\hline 5 & Give test dose, $D_{\mathrm{t}}$ & \\
\hline 6 & Preheat at 250 or $320^{\circ} \mathrm{C}$ for $60 \mathrm{~s}^{b}$ & \\
\hline 7 & IRSL measurement at T1 for $200 \mathrm{~s}$ & $T_{x(50)}$ \\
\hline 8 & IRSL measurement at T2 for $200 \mathrm{~s}$ & $T_{x(T)}$ \\
\hline 9 & IR bleaching at $325^{\circ} \mathrm{C}$ for $40 \mathrm{~s}$ & \\
\hline 10 & Return to step 1 & \\
\hline \multicolumn{3}{|c|}{ MET-pIRIR protocol } \\
\hline 1 & Give regenerative dose, $D_{\mathrm{i}}^{\mathrm{a}}$ & \\
\hline 2 & Preheat at $320^{\circ} \mathrm{C}$ for $60 \mathrm{~s}$ & \\
\hline 3 & IRSL measurement at $50^{\circ} \mathrm{C}$ for $100 \mathrm{~s}$ & $L_{x}(50)$ \\
\hline 4 & IRSL measurement at $100^{\circ} \mathrm{C}$ for $100 \mathrm{~s}$ & $L_{x}(100)$ \\
\hline 5 & IRSL measurement at $150^{\circ} \mathrm{C}$ for $100 \mathrm{~s}$ & $L_{x}(150)$ \\
\hline 6 & IRSL measurement at $200^{\circ} \mathrm{C}$ for $100 \mathrm{~s}$ & $L_{x(200)}$ \\
\hline 7 & IRSL measurement at $250^{\circ} \mathrm{C}$ for $100 \mathrm{~s}$ & $L_{x(250)}$ \\
\hline 8 & IRSL measurement at $300^{\circ} \mathrm{C}$ for $100 \mathrm{~s}$ & $L_{x(300)}$ \\
\hline 9 & Give test dose, $D_{\mathrm{t}}$ & \\
\hline 10 & Preheat at $320^{\circ} \mathrm{C}$ for $60 \mathrm{~s}$ & \\
\hline 11 & IRSL measurement at $50^{\circ} \mathrm{C}$ for $100 \mathrm{~s}$ & $T_{x(50)}$ \\
\hline 12 & IRSL measurement at $100^{\circ} \mathrm{C}$ for $100 \mathrm{~s}$ & $T_{x(100)}$ \\
\hline 13 & IRSL measurement at $150^{\circ} \mathrm{C}$ for $100 \mathrm{~s}$ & $\mathrm{~T}_{\mathrm{x}(150)}$ \\
\hline 14 & IRSL measurement at $200^{\circ} \mathrm{C}$ for $100 \mathrm{~s}$ & $\mathrm{~T}_{\mathrm{x}(200)}$ \\
\hline 15 & IRSL measurement at $250^{\circ} \mathrm{C}$ for $100 \mathrm{~s}$ & $\mathrm{~T}_{\mathrm{x}(250)}$ \\
\hline 16 & IRSL measurement at $300^{\circ} \mathrm{C}$ for $100 \mathrm{~s}$ & $\mathrm{~T}_{\mathrm{x}(300)}$ \\
\hline 17 & IR bleaching at $325^{\circ} \mathrm{C}$ for $100 \mathrm{~s}$ & \\
\hline 18 & Return to step 1 & \\
\hline
\end{tabular}

a For the 'natural' and sunlight-bleached samples, $i=0$ and $D_{0}=0$. The whole sequence is repeated several times using a series of different regenerative doses including a zero dose and a repeat dose.

${ }^{b}$ For the $\operatorname{pIRIR}(50,225)$ method (Buylaert et al., 2009), the preheat temperature is $250^{\circ} \mathrm{C}$. For the pIRIR(50, 290) method (Thiel et al., 2011a), the preheat temperature is $320^{\circ} \mathrm{C}$. 
fading rate of the pIRIR $(50,225)$ signal is significantly lower than for the corresponding $50^{\circ} \mathrm{C}$ IRSL signal, and the magnitude of the fading correction largely reduced. Similar observations were reported in subsequent studies (e.g., Buylaert et al., 2009; Alappat et al., 2010; Lowick et al., 2012; Sohbati et al., 2012; Vasiliniuc et al., 2012). In Fig. 1a and 1b, we have compared the g-values calculated for the $50^{\circ} \mathrm{C}$ IRSL and $\operatorname{pIRIR}(50,225)$ signals provided in previously published studies (see Table $\mathbf{S 1}$ for values and references). The frequency histograms of the same data sets are also shown in Fig. 1c. It shows large sample-to-sample variation in g-values obtained for the $50^{\circ} \mathrm{C}$ IRSL signal (from $\sim 1$ to $\sim 15 \% /$ decade). This contrasts with the results obtained for the $\operatorname{pIRIR}(50,225)$ signal for which all, but two, of the samples had g-values that fall within a narrow range of $\sim 0.5$ to $\sim 3 \%$ /decade. In addition, the pIRIR $(50,225)$ g-values are also systematically smaller than those observed for the $50^{\circ} \mathrm{C}$ IRSL signal (Fig. 1a and 1b) with average fading rates of
$3.7 \pm 0.3$ and $1.5 \pm 0.1 \%$ /decade for the $50^{\circ} \mathrm{C}$ IRSL and pIRIR(50, 225) signals, respectively. If we were to use these two g-values to correct the age of a sample with an apparent age of $50 \mathrm{ka}$, using the method of Huntley and Lamothe (2001) and assuming that both the g-values and $D_{\mathrm{e}}$ values were normalised to a delay time $\left(t_{\mathrm{c}}\right)$ of 2 days, the percentage age correction would be $\sim 32$ and $\sim 11 \%$, respectively. The uncertainty on the age associated with the fading correction for the $\operatorname{pIRIR}(50,225)$ signal is, therefore, significantly reduced compared to the age correction for the $50^{\circ} \mathrm{C}$ IRSL, as previously shown by Buylaert et al. (2009).

Following the initial work of Thomsen et al. (2008) and Buylaert et al. (2009), Thiel et al. (2011a) proposed a modified method to measure the pIRIR signal following a higher preheat temperature $\left(320^{\circ} \mathrm{C}\right.$ compared to $\left.250^{\circ} \mathrm{C}\right)$ and IR stimulation at a higher temperature $\left(\mathrm{T} 2=290^{\circ} \mathrm{C}\right.$ compared to $\left.225^{\circ} \mathrm{C}\right)$ (i.e., pIRIR $(50,290)$ ). This method (pIRIR(50, 290)) was subsequently tested in thirteen
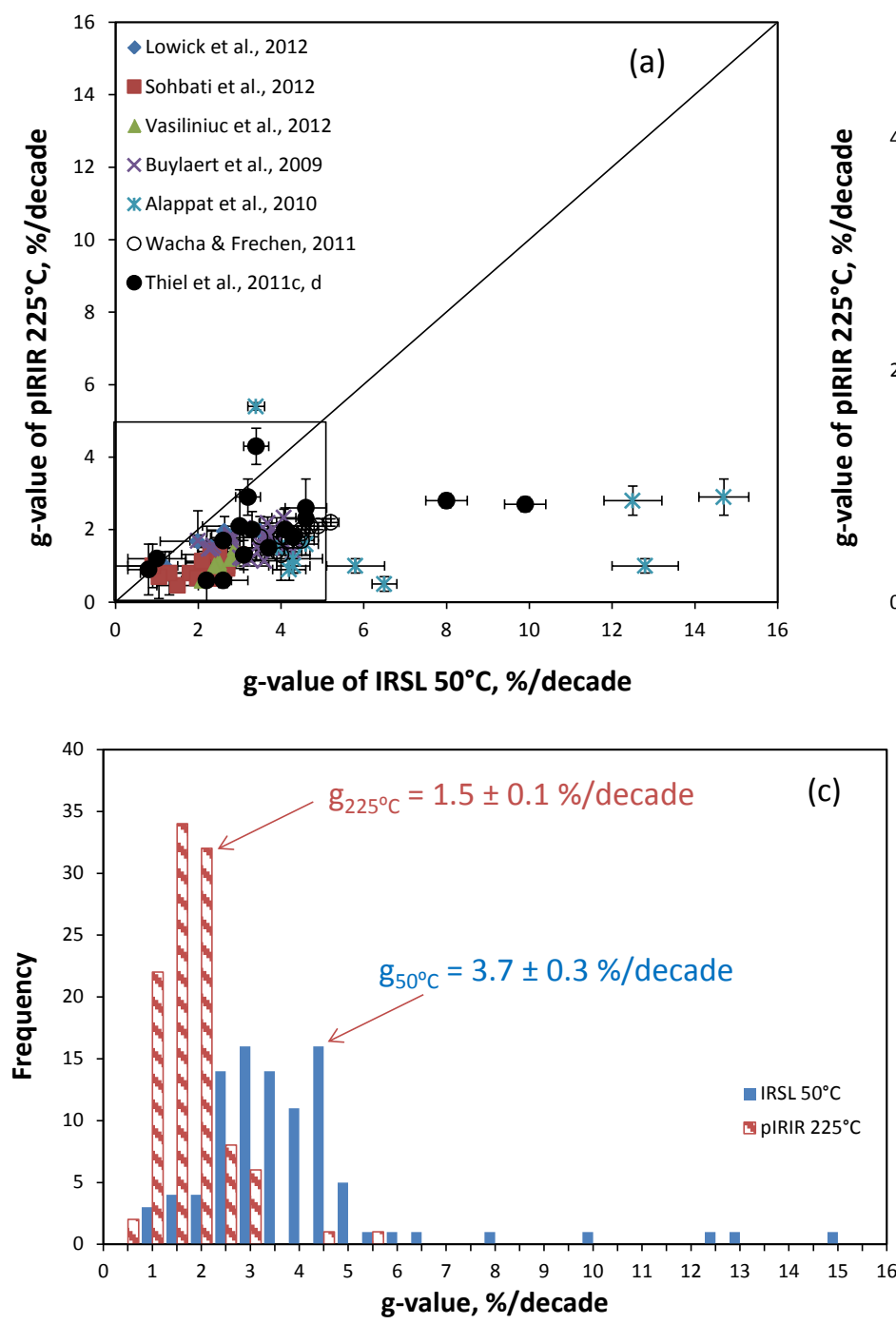

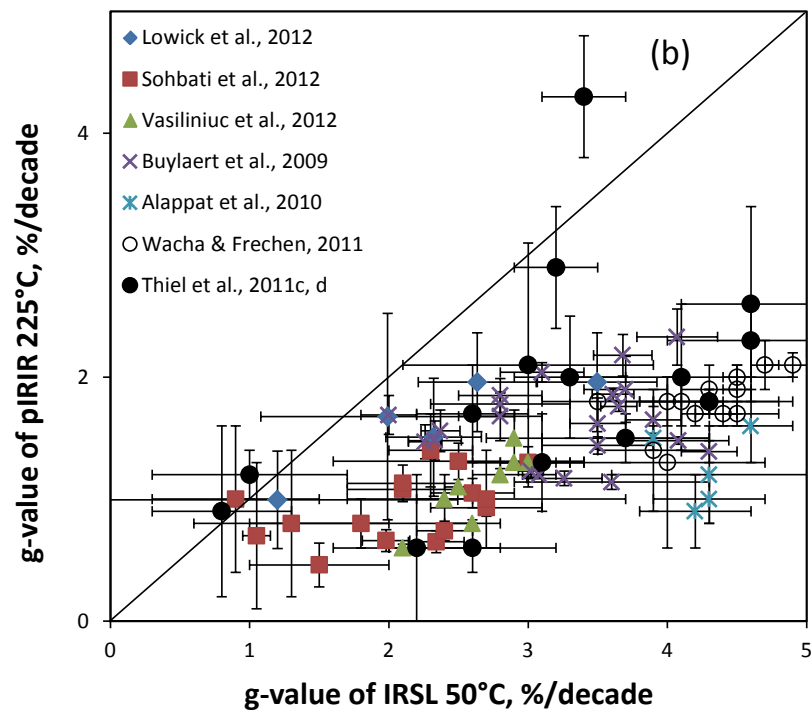

Fig. 1. (a) Comparison of $g$-values obtained using the $50^{\circ} \mathrm{C} I R S L$ and $\operatorname{pIRIR}(50,225)$ signals reported in previous studies (see Table S1 for original data). The data inside the square is shown in (b). (c) The g-values shown in (a) presented as a histogram. The text in (c) shows the overall average fading rates for the $50^{\circ} \mathrm{C} I R S L$ and $\operatorname{PIRIR}(50,225)$ signals. 
different studies (see summary in Table $\mathbf{S} 1$ and reference therein). All measured g-values reported in the 13 studies are provided in Table $\mathbf{S 1}$ and those g-values calculated for the pIRIR(50, 290) signal are summarised in Fig. 2 and compared to those obtained for the $\operatorname{pIRIR}(50,225)$ signal. Note that the g-values for the two signals shown in Fig. 2 are not all on the same set of samples. A range of g-values between $\sim 0$ and $\sim 5 \%$ /decade was observed for different samples from different regions of the world, and most of the values fall between $\sim 0.5$ and $\sim 2 \% /$ decade. An average value of $1.1 \pm 0.1 \%$ /decade is calculated for the $\operatorname{pIRIR}(50,290)$ signal, and this is smaller than the average value of $1.5 \pm 0.1 \% /$ decade obtained for the pIRIR $(50,225)$ signal.

There are 37 samples from 6 different studies for which g-values and ages were calculated using both pI$\operatorname{RIR}(50,225)$ and $\operatorname{pIRIR}(50,290)$ (Buylaert et al., 2009, 2011, 2012; Thiel et al., 2011c; Lowick et al., 2012; Vasiliniuc et al., 2012); the g-values are compared in Fig. 3a. This data set represents samples from a range of geographic regions and different depositional environments, including loess, aeolian, coastal and waterlain sediments. Sixy-five percent of the samples $(n=24)$ have g-values for both signals that are statistically consistent with each other at $2 \sigma$ and range between $2.0 \pm 0.4$ and $0.6 \pm 0.2 \% /$ decade for the $\operatorname{pIRIR}(50,225)$ signal and between $3.7 \pm 1.3$ and $0.6 \pm 0.1 \%$ /decade for the pI$\operatorname{RIR}(50,290)$ signal. The remaining $35 \%$ of the samples $(n=13)$ have g-value for the pIRIR(50, 290) signal (g290-value) that are all smaller than the corresponding g-values for the pIRIR $(50,225)$ signal (g225-value); the g225values range between $2.9 \pm 0.5$ and $1.2 \pm 0.03$ $\% /$ decade and the g290-values range between $1.53 \pm 0.05$ and $-0.4 \pm 0.05 \% /$ decade. Where there is consistency, the g225-values are on average larger than those that show no consistency with their corresponding g290values at $2 \sigma$ (Fig. 3a).

Fig. $3 \mathbf{b}$ shows the fading-uncorrected ages for the same set of samples for which fading rates are provided in Fig. 3a; note that 5 of the 37 samples are not shown as their ages are only reported as minimum ages without error estimates (see Table S1). The different symbols differentiate between those samples that have consistent g-values at $2 \sigma(\mathrm{g} 225=\mathrm{g} 290$; circles $)$, and those that have g225-values that are larger than their corresponding g290-values (g225 > g290; squares). Fig. 3b shows good agreement between ages obtained from both methods for samples $<100 \mathrm{ka}$ (see inset plot). This is consistent with the g-values that are either consistent or relatively small $(<\sim 2 \% /$ decade $)$. For those samples $>100 \mathrm{ka}$ it appears that the pIRIR290 age on average overestimate relative to their corresponding pIRIR225 ages, shown by the majority of samples falling above the 1:1 line (solid line). We have also fitted a weighted linear fit to all the samples $>20$ ka presented in Fig. 3b (indicated as a broken line); the slope of the line is $1.20 \pm 0.03$ and the interception is $1.9 \pm 1.5 \mathrm{ka}$ on the y-axis. We omitted the $<20 \mathrm{ka}$ sam-

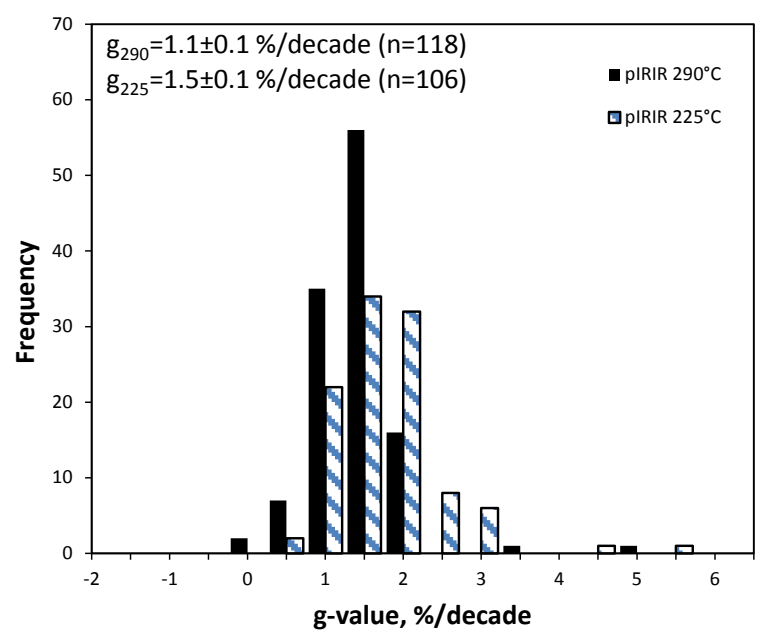

Fig. 2. A summary of the g-values measured using $p I R I R(50,290)$ and those using pIRIR(50, 225) signals in previous studies (see Table S1 for original data). The text in the figure shows the average fading rates for the two signals.

ples as these may be affected by the presence of a relatively large residual dose (see below). This pattern does not change if we omit the two oldest ages that were reported to be in, or close to, saturation (Vasiliniuc et al., 2012). Since the pIRIR290 signal is more likely to be incompletely bleached than the pIRIR225 signal, it is important to ensure that the samples were well-bleached at the time of deposition. Among the samples presented in Fig. 3b, most of them are aeolian sediments, which are expected to have been well-bleached. Exceptions are two waterlain samples (GOS3 and ZEL7) from Switzerland (Lowick et al., 2012), which may have been incompletely bleached, although one of them (GOS3) was considered well-bleached by the authors, based on the fact that the ages obtained from a variety of luminescence signals were in agreement with uranium-series and radiocarbon ages (Lowick et al., 2012). If we discard these two samples from our analysis, however, the pattern shown in Fig. $3 \mathbf{b}$ does not change. Thus we consider that the overestimation in pIRIR290 ages relative to pIRIR225 ages shown in Fig. 3b is not due to the problem of insufficient bleaching.

To further scrutinise the results, we have plotted the same data in Fig. 3c but this time as age ratios (pIRIR290 / pIRIR225) plotted from youngest on the left to oldest on the right using their $\operatorname{pIRIR}(50,290)$ ages for ranking. From here it can be seen that 2 of the 5 samples $(40 \%)$ younger than $20 \mathrm{ka}, 7$ of the 9 samples $(78 \%)$ between $\sim 20$ and $100 \mathrm{ka}$, and 9 of the 18 samples $(50 \%)$ older than $100 \mathrm{ka}$ have fading-uncorrected ages consistent with each other at $2 \sigma$. The difference in age is, therefore, most conspicuous not only for those samples older than $\sim 100 \mathrm{ka}$, but also for young samples $(<20 \mathrm{ka})$. Importantly, there is no direct relationship between consistency in fading rate 

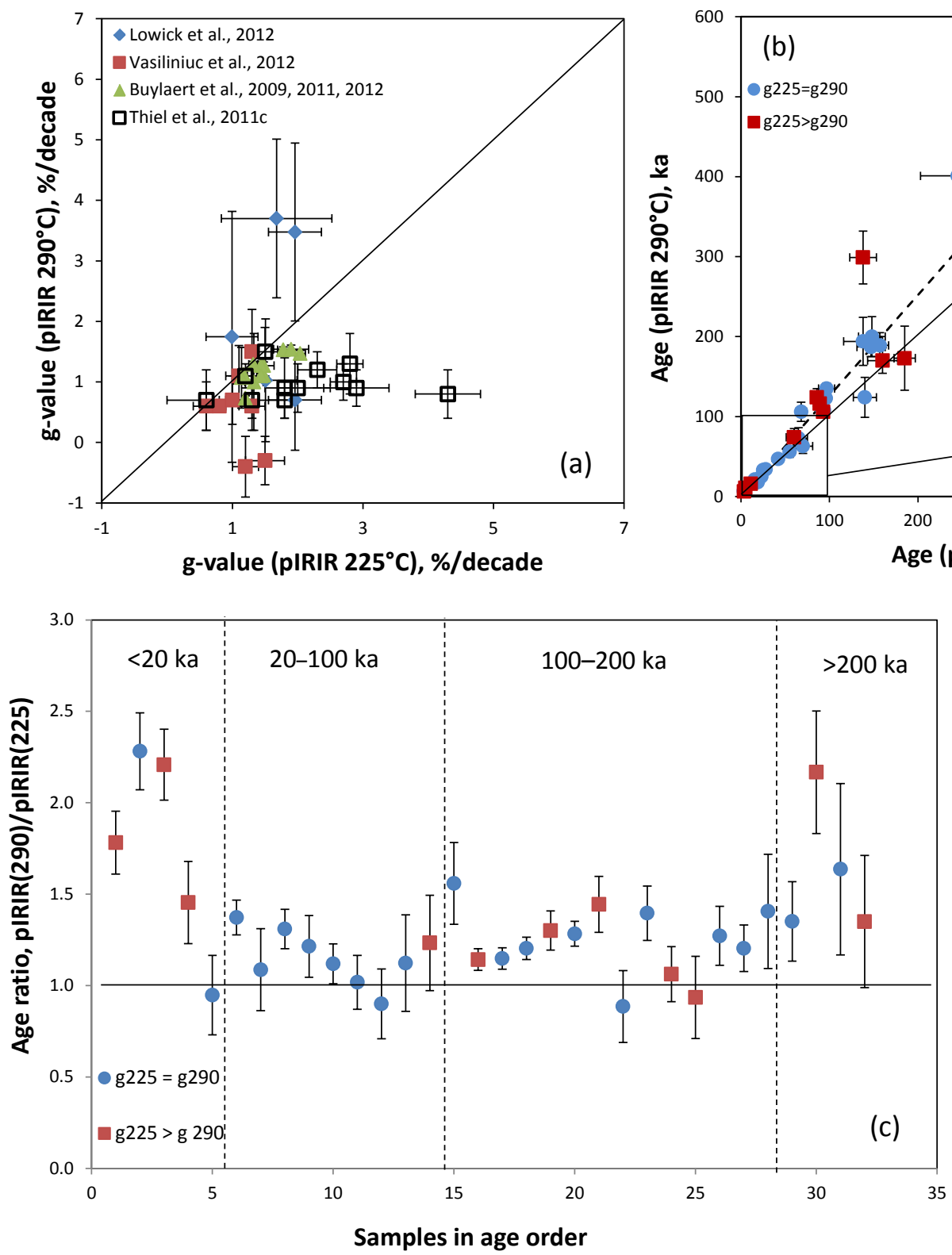

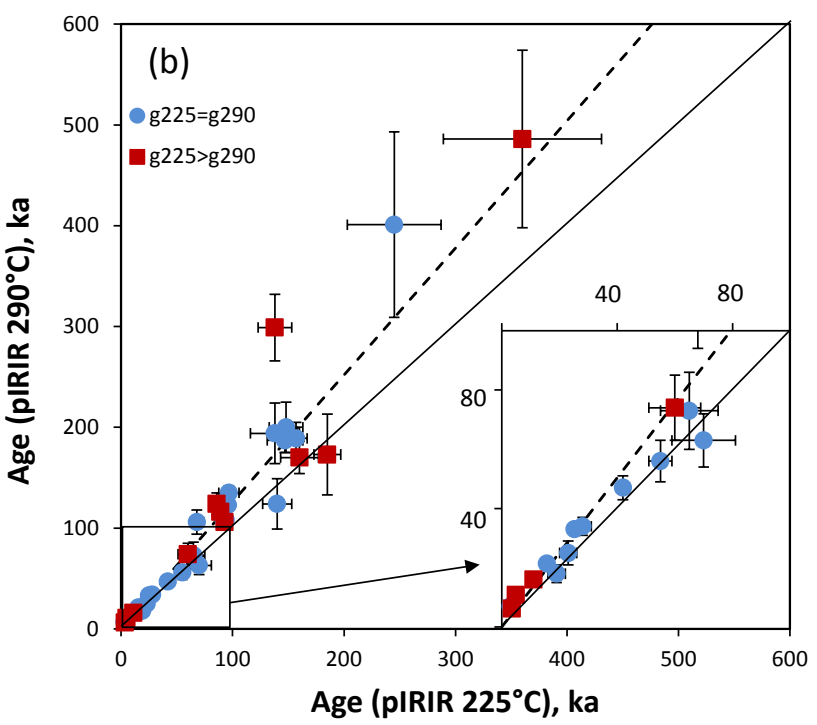

Fig. 3. (a) Comparison between the $g$ values obtained in previous studies for the $\operatorname{pIRIR}(50,225)$ and $\operatorname{pIRIR}(50,290)$ signals (see Table S1 for original data). (b) Comparison between the fading uncorrected ages of the $\operatorname{pIRIR}(50,225)$ and $p I R I R(50,290)$ signals for the same samples shown in (a). The solid line shows the 1:1 relationship, and the dashed line is the weighted linear fit of the whole data set (slope =1.22). The inset shows the enlarged scale for the data between 0-100 ka. (c) The same data of (b) plotted as age ratios against pIRIR(50, 290) ages ranked in order (from the youngest at the left to the oldest at the right). and age; samples with g225 = g290 value can have consistent and inconsistent ages between the two signals and the same is true for samples with g225>g290 values. A weighted mean ratio (pIRIR290/pIRIR225) of $1.21 \pm 0.05$ for the ages of samples older than $20 \mathrm{ka}$ suggests that the $\operatorname{pIRIR}(50,290)$ ages are on average older than their respective pIRIR $(50,225)$ ages by $\sim 20 \%$. The weighted mean ratio for the samples between 20 and $100 \mathrm{ka}$ is $1.19 \pm 0.05$ and for those $>100 \mathrm{ka}$ the ratio is $1.22 \pm 0.07$; the latter ratio changes to $1.21 \pm 0.07$ if the two oldest samples are omitted. So, even though there appear to be a systematic trend with age, the differences are similar on average regardless of age.

Several possible reasons may explain the systematic overestimation in age for the $\operatorname{pIRIR}(50,290)$ signal com- pared to the $\operatorname{pIRIR}(50,225)$ signal. 1) The first explanation is that a small difference in fading rate between the two pIRIR signals could result in a large difference in apparent age. We can use the $>20 \mathrm{ka}$ samples shown in Fig. 3 as a point in case. For these samples the pIRIR(50, 290 ) ages are on average $\sim 20-30 \%$ older than their corresponding pIRIR(50, 225) ages (Fig. 3b). The average gvalue for the pIRIR $(50,225)$ signal is $1.5 \% /$ decade and for the $\operatorname{pIRIR}(50,290)$ signal, $1.1 \% /$ decade. If the true age of the samples is $50 \mathrm{ka}$ and we use these average gvalues to calculated apparent ages, using the equation of Huntley and Lamothe (2001), then apparent ages of $\sim 45$ and $\sim 46 \mathrm{ka}$ are obtained. Note that this difference will become larger for older samples where the fading correction method is not applicable. The difference in age, 
however, will still be too large to be explained by differences in the g-values, and the difference in age can, therefore, not be explained by the difference predicted by the laboratory-measured fading rates.

A second explanation, first proposed by Thiel et al. (2011a), is that the fading rates measured in the laboratory for the pIRIR(50, 290) signal are artefacts (i.e., they are not real). They found support in this from natural pIRIR $(50,290)$ signals measured for infinitely old samples that are close to or in dose saturation, compared to natural pIRIR $(50,225)$ signals for the same samples that are consistently found to be $\sim 15-20 \%$ below saturation. So, following this argument, a number of recent studies have proposed that the $\operatorname{pIRIR}(50,290)$ signal is stable and does not fade, and that the difference in age between the two pIRIR signals are due to the fading of one, but not the other (Thiel et al., 2011a; Stevens et al., 2011; Buylaert et al., 2012). If this is the case, then there will also be systematic errors associated with the dose response curves (DRC) and the estimated $D_{\mathrm{e}}$ values because the same SAR procedure is used for estimation of the fading rate and construction of DRCs. The extent of the introduced error on the different measurements and components will, however, be significantly different and should be assessed separately (i.e., a small change in the g-value can significantly change the age, whereas a small change in the DRC or $D_{\mathrm{e}}$ may not be so important). One would, however, expect the recycling ratio for the pI$\operatorname{RIR}(50,290)$ signal to deviate systematically from unity if the fading rate is an apparent result of a systematic decrease of the repeated measurement of the regenerative-dose signals in the SAR cycles in the fading test. This is, however, not supported by the result of a large number of recycling ratios that are consistent with unity (see Fig. 3A in Buylaert et al. (2012)). What also remains unclear is why the one signal $(\operatorname{pIRIR}(50,225))$ would fade and not the other (pIRIR $(50,290))$. The measurement conditions of the two signals are different in terms of preheat temperature $\left(250^{\circ} \mathrm{C}\right.$ for $\operatorname{pIRIR}(50,225)$ and $320^{\circ} \mathrm{C}$ for $\left.\operatorname{pIRIR}(50,290)\right)$ and the pIRIR stimulation temperature $\left(225\right.$ and $\left.290^{\circ} \mathrm{C}\right)$. Both signals are measured after the prolonged $50^{\circ} \mathrm{C}$ IRSL stimulation that is used to deplete the 'easy-to-fade' donor-acceptor pairs. If this stimulation did not remove the entire fading component, then the remainder should presumably be sampled by the subsequent pIRIR measurement, regardless of whether it is measured at $225^{\circ} \mathrm{C}$ or $290^{\circ} \mathrm{C}$. The higher preheat temperature used for $\operatorname{pIRIR}(50,290)$ could also remove more easy-to-fade electron-hole pairs and, therefore, leave more difficult-to-fade components in the subsequent IRSL signals (e.g., Jain and Ankjærgaard, 2011). This high preheat temperature, however, does not eliminate the fading component completely, because the subsequent IRSL $50^{\circ} \mathrm{C}$ signal still yields a large fading rate (Fig. $1 \mathrm{~b}$ ). It is reasonable to deduce, therefore, that the lower fading rate observed in $\operatorname{pIRIR}(50,290)$ signal is due mainly to the higher stimulation temperature used, although a high- er preheat temperature may still play a role. Following this logic, either both signals should fade (although may be to different extents), or both signals do not fade and the measured fading rates are laboratory artefacts. If both measured fading rates are artefacts, then both signals should give similar ages; this is true for some, but not all of the samples shown in Fig. 3b and 3c.

A third possible explanation was proposed by Vasiliniuc et al. (2012) and Chen et al. (2013) who suggested that the $D_{\mathrm{e}}$ obtained using the $\operatorname{pIRIR}(50,290)$ signal is overestimated in some samples because of an unsuccessful sensitivity correction of the first measurement (i.e., the natural signal). Fading rate measurements do not involve measurement of the natural signal either in $D_{\mathrm{e}}$ or dose recovery measurements, so the problem of the sensitivity correction of the natural is avoided. If this explanation is true, then the pIRIR $(50,290)$ ages for old samples (e.g., >100 ka) should be treated with caution because any slight error in the sensitivity correction will result in a relatively large uncertainty in the large dose range of DRCs. This possibility can, however, be tested by conducting a dose recovery test (see section 4). Apart from the problem of natural sensitivity correction, the presence of an isothermal signal (Fu et al., 2012a; Wang and Wintle, 2013) was also proposed to be a potential problem for measurement of the natural dose and overestimation of the age. We note that any pIRIR signal can contain some thermal signal, especially when the difference between the preheat and pIRIR stimulation temperatures is small (i.e., 25 and $30^{\circ} \mathrm{C}$ for $\operatorname{pIRIR}(50,225)$ and $\operatorname{pIRIR}(50,290)$ signals, respectively). However, the effect of the isothermal signal on $D_{\mathrm{e}}$ estimation may differ between the two pIRIR signals, due to the large difference in thermal stability of the 225 and $290^{\circ} \mathrm{C}$ signals. In both cases, one should monitor for and wait long enough to reduce the thermal signal before starting IR stimulation (Fu et al., 2012a).

\section{Multi-step post-IR IRSL}

$\mathrm{Li}$ and $\mathrm{Li}$ (2011a) proposed a multi-step pIRIR procedure (Table 1), the so-called multi-elevated-temperature post-IR IRSL (MET-pIRIR) protocol as an alternative to the two-step procedures. This method is based on the observation that the fading component in the IRSL signal can be progressively eliminated using multiple IR stimulations by increasing the stimulation temperature from 50 to $250^{\circ} \mathrm{C}$ in $50^{\circ} \mathrm{C}$ intervals. Laboratory fading tests for a feldspar sample showed that the highest anomalous fading rate is observed for the $50^{\circ} \mathrm{C}$ IRSL, and it decreases as the stimulation temperature is increased. Negligible anomalous fading rates were observed for the signals obtained at $250^{\circ} \mathrm{C}$ (Fig. S2) (Li and Li, 2011a; 2012a).

One advantage of the MET-pIRIR protocol over the two-step pIRIR protocol is that the effect of anomalous fading can be demonstrated in an Age_Temperature (A-T) or a $D_{e_{-}}$Temperature $\left(D_{e}-T\right)$ plot, in which the calculated ages or $D_{\mathrm{e}}$ are plotted as a function of IR 
stimulation temperature (Fig. 4). The A-T (or $\mathrm{D}_{\mathrm{e}}-\mathrm{T}$ ) plot shows how the ages increase with increased stimulation temperature until an age plateau (shown as a broken line in Fig. 4) is reached at higher temperatures; this plateau indicates that a non-fading component was isolated at elevated temperatures. The age plateau could, therefore, be used as a internal diagnostic tool for checking whether a stable, non-fading component has been achieved or not. The MET-pIRIR protocol was first tested using various sedimentary samples from northern China deposited over the last $\sim 130 \mathrm{ka}$ (Li and Li, 2011a). For all of the samples, the youngest ages were obtained using $50^{\circ} \mathrm{C}$ IRSL from where ages obtained for subsequently measured MET-pIRIR signals started to increase as a function of an increase in stimulation temperature until an age or $D_{\mathrm{e}}$ plateau is obtained above $200^{\circ} \mathrm{C}$. This method was subsequently tested on loess samples from the Luochuan section of the Chinese Loess Plateau ( $\mathrm{Li}$ and $\mathrm{Li}, 2012 \mathrm{a}$ ). In Fig. 4, we compiled a summary A-T or $D_{e}-T$ plot containing data of 46 samples from Northern China, India and Europe (see Table S1 for samples, $D_{\mathrm{e}}$ values and ages). To facilitate comparisons, all ages or $D_{\mathrm{e}}$ values were first normalised to 1 at $250^{\circ} \mathrm{C}$. The samples were divided into four groups according to their age (i.e., $<50$, $50-100,150-200$ and $>200 \mathrm{ka}$ ) and the average values of the samples from each group was calculated and shown in Fig. 4. The error on each average value is the $1 \sigma$ standard deviation. It is observed that the temperature at which the plateau is reached varies with age. Younger samples

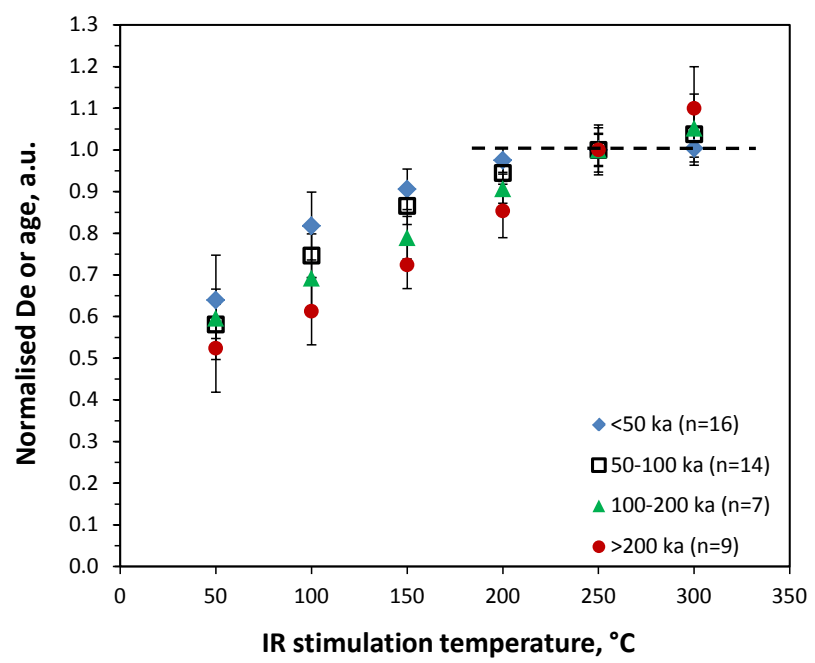

Fig. 4. Normalised ages (or $D_{e}$ ) plotted against IR stimulation temperature for different samples in different age ranges $(<50,50-100$, 100-200 and >200 ka). The MET-pIRIR ages were normalised to unity at $250^{\circ} \mathrm{C}$, and then averaged for each group. The dashed horizontal line shows the normalised value at 1 . The number of samples (n) used to produce the data set is shown in the legend. Note that the data point at $300^{\circ} \mathrm{C}$ for the data set of $>200 \mathrm{ka}$ is based on 3 samples only because most of the samples have saturated MET-pIRIR $300^{\circ} \mathrm{C}$ signals, although the signals obtained at lower temperatures were not saturated for the 9 samples investigated.
$(<50 \mathrm{ka})$, appear to reach the plateau at $\sim 200^{\circ} \mathrm{C}$, whereas older samples (50-200 ka) only reach the plateau at $\sim 250^{\circ} \mathrm{C}$. The data set for the oldest samples $(>200 \mathrm{ka})$, however, appears to be keep increasing with stimulation temperature - that is, the normalised $D_{\mathrm{e}}$ value at $300^{\circ} \mathrm{C}$ is $1.1 \pm 0.1$ for these samples. Note that the latter value is based on 3 samples only, because most of the samples have saturated MET-pIRIR $300^{\circ} \mathrm{C}$ signals; the signals obtained at lower temperatures were not saturated for the 9 samples investigated. The results of Fig. 4 indicate that the MET-pIRIR $200^{\circ} \mathrm{C}$ signal (and probably the $250^{\circ} \mathrm{C}$ signal also) still suffers from a small amount of fading, which has a negligible effect on young samples (e.g., $<50 \mathrm{ka}$ ), but that manifest itself in a more significant underestimation of age or $D_{\mathrm{e}}$ in older samples. Fu and $\mathrm{Li}$ (2013) also reported that an age plateau, consistent with the expected age for their Holocene-age samples, can be achieved at temperatures as low as $\sim 150^{\circ} \mathrm{C}$. Another important feature of Fig. 4 is that older samples tend to show a larger difference in age or $D_{\mathrm{e}}$ between lowtemperature IRSL and high-temperature MET-pIRIR, suggesting that older samples have a higher effective anomalous fading rate associated with the lowtemperature IRSL signal ( $\mathrm{Li}$ and $\mathrm{Li}, 2008$ ).

Another advantage of the A-T plot is that it can be used as an indicator of insufficiently bleached samples. An insufficiently bleached sample is unlikely to give an age plateau when plotted as an A-T plot, because the MET-pIRIR signals obtained at higher temperatures are more difficult to bleach than the low temperature signals ( $\mathrm{Li}$ and $\mathrm{Li}, 2011 \mathrm{a}$ ). When using the A-T plot to diagnose the problem of insufficient bleaching, two factors bleaching and fading - must be considered. Both can influence the pattern of the plateau, and this may cause difficulty in distinguishing partial bleaching from fading. As indicated by Fig. 4, however, such difficulties can mostly affect older samples (e.g., >200 ka), as even a small anomalous fading could significantly affect the ages. For younger samples, assessing incomplete bleaching is usually more important and fading can be compensated for more effectively by making a laboratory fading test; the A-T plot can then be used to diagnose the existence or absence of insufficient bleaching.

The MET-pIRIR method was subsequently tested by Thomsen et al. (2012) who measured 9 samples using both the MET-pIRIR and the pIRIR $(50,290)$ protocols. They suggested that no significant difference was observed between the results obtained from both methods for their samples, indicating that the prior-IR stimulation temperature may not be important and a single IR stimulation at $50^{\circ} \mathrm{C}$ may be sufficient to remove the fading component. The two methods were also tested by $\mathrm{Li}$ and Li (2012b) using loess samples from the Chinese Loess Plateau. They found that the pIRIR(50, 290) give comparable results for those samples with relatively small natural doses (e.g., $<500 \mathrm{~Gy}$ ), which is consistent with the findings reported by Thomsen et al. (2012). But, the 
pIRIR $(50,290)$ signal starts to underestimate relative to the MET-pIRIR ages for older samples with larger natural doses ( $>500 \mathrm{~Gy})$, suggesting that a small fading component may still be present in the pIRIR $(50,290)$ signal and, although it is not a problem for young samples, it becomes more important for older samples.

The validity of the MET-pIRIR method has so far only been tested on a small number of samples from China where independent age control is available, and its general applicability to samples from different geographical locations and depositional environments are currently been tested.

\section{BEHAVIOUR OF THE POST-IR IRSL SIGNALS}

\section{Thermal stability}

One of the crucial assumptions in OSL dating is that the trapped electrons used for dating are stable over the time of burial. It is thus important to ensure that the luminescence signals used for dating are associated with stable traps that have a long lifetime at ambient temperature (e.g., $\sim 10-20^{\circ} \mathrm{C}$ ). There have been several studies of the thermal stability of the IRSL signal for K-feldspar grains extracted from sediments (Spooner, 1994; Li and Tso, 1997; Li et al., 1997; Murray et al., 2009; Baril and Huntley, 2003). Focusing on the initial part of the IRSL signal obtained by stimulating at $\sim 50^{\circ} \mathrm{C}$, Li et al. (1997) suggested that the IRSL traps are associated with deep traps with a thermal depth of $\sim 1.7 \mathrm{eV}$ (Li et al., 1997), which have a lifetime of $\sim 10^{9}$ years. A similar result was obtained by Murray et al. (2009). Based on the reduction of TL from IR bleaching, they suggested that the IRSL traps of their K-feldspar sample mainly originated from deep traps associated with the $\sim 410^{\circ} \mathrm{C} \mathrm{TL}$ peak. In a later study on the effect of IR bleaching on the TL of Kfeldspar from sediments from North China, $\mathrm{Li}$ and $\mathrm{Li}$ (2011b) found that the IRSL are associated with the 350 and $400^{\circ} \mathrm{C}$ TL peaks, which led them to suggest that at least two groups of traps (shallow and deep) are associated with the IRSL signals. All these studies suggest that the IRSL signal from K-feldspar is thermally stable over the datable period (e.g., $<1 \mathrm{Ma}$ ). However, based on isothermal studies of IRSL and pIRIR signals, $\mathrm{Li}$ and $\mathrm{Li}$ (2013) suggested that, although originated from deep traps, a part of the IRSL signal is still thermally unstable due to the presence of the band-tail states (Poolton et al., 2002; Poolton et al., 2009). They suggested that a preheat temperature above $200^{\circ} \mathrm{C}$ is necessary to remove these unstable signals.

The thermal stability of the pIRIR signal was investigated in several studies ( $\mathrm{Li}$ and $\mathrm{Li}, 2011 \mathrm{~b}$; Thomsen et al., 2011; Fu et al., 2012b; Li and Li, 2013). Based on a pulse anneal study of the IRSL and pIRIR signals on the K-feldspar grains from several sedimentary samples, Thomsen et al. (2011) showed that the pIRIR signal has a greater thermal stability than the $50^{\circ} \mathrm{C}$ IRSL signal (e.g., heating to $\sim 400^{\circ} \mathrm{C}$ can erase most of the $50^{\circ} \mathrm{C}$ IRSL signal, whereas the $\operatorname{pIRIR}(50,290)$ signal is still not completely erased by heating to $\sim 550^{\circ} \mathrm{C}$ ). $\mathrm{Li}$ and $\mathrm{Li}(2011 \mathrm{~b}$ ) studied the thermal stability of the IRSL and MET-pIRIR signals from K-feldspar grains. Based on their pulse anneal studies, they suggested that the MET-pIRIR signals at elevated temperatures $\left(>100^{\circ} \mathrm{C}\right)$ are more thermally stable than the IRSL signal at $50^{\circ} \mathrm{C}$, due to the presence of deeper traps in the MET-pIRIR signals. It has, however, been suggested that the difference in thermal stabilities can be explained using a single-trap model. Based on a time-resolved stimulation study, Jain and Ankjærgaard (2011) suggested that the low temperature IRSL signal and the pIRIR signal have different recombination routes; the former are dominated by recombination of spatially close electron-hole pairs and the latter are dominated by recombination of distant electron-hole pairs. They, therefore, argued that the observed difference in the thermal stabilities of IRSL and pIRIR signals can be explained as a single-trap model with the presence of band-tail states. Andersen et al. (2012) produced direct spectroscopic evidence that also favours a single-trap model. It is, however, difficult to explain, with a single-trap model, the different dose response curve shapes obtained from measurement of different IRSL and pIRIR signals (see section 4), and their different bleaching rates under highenergy stimulation (e.g., sunlight bleaching) (see section 4). Andersen et al. (2012), however, suggested that the differences in DRC shapes may be kinetic rather than a multiple trap effect. The debate about whether it is a single- or multiple-trap model is still ongoing and more data will no doubt be provided in future studies in support of one or the other of these models.

\section{Bleachability and residuals}

Another crucial precondition for luminescence dating of sediment is that the signals measured in the laboratory should be bleachable by sunlight. Although the pIRIR signals measured at elevated temperature have significantly reduced rates of fading compared to the IRSL signal measured at low temperatures (Fig. 1c), they have also been found to be more difficult to bleach (Thomsen et al., 2008; Li and Li, 2011a). Fig. S1 shows the solar bleaching experiments for IRSL and pIRIR signals reported by Buylaert et al. (2012) and Li and Li (2011a). Both studies showed that, at higher stimulation temperatures, the IRSL signal consists of components that are more resistant to sunlight bleaching, and it requires up to several hours of exposure to simulated sunlight in a solar simulator to empty most of the light-sensitive pIRIR traps. The relatively harder-to-bleach nature of the pIRIR signals, compared to the fast bleaching rate in quartz OSL, can be used to identify well-bleached quartz grains (Murray et al., 2012), or can be used to identify poorly bleached feldspar grains.

A feature of the pIRIR signals, however, is that there is a non-bleachable (or residual) component left even 
after a prolonged bleaching period. This manifests itself as a 'residual dose' when modern and sun-bleached sediments are measured. Apart from the 'non-bleachable' component, the residual doses observed in the pIRIR signals may also be partly induced by thermal transfer of charge from unstable light-insensitive traps into the IRSL and pIRIR traps due to the high preheat temperature $\left(>300^{\circ} \mathrm{C}\right)$ used in the pIRIR protocols (Buylaert et al., 2012). No matter which source the residual dose is from, it needs to be taken into consideration for $D_{\mathrm{e}}$ estimation.

In previous studies, estimates of the size of the residual dose have been made from measurements of modern analogues or samples of interest that have been artificially bleached with a solar simulator or natural sunlight. A small residual dose up to a few Gy in the pIRIR signal has been reported (e.g., Thomsen et al., 2008; Li and Li, 2011a; Fu et al., 2012a), suggesting that it is only important to consider the residual doses for relatively young samples (e.g., $D_{\mathrm{e}}<100 \mathrm{~Gy}$ ). Significantly higher residual doses have subsequently been reported by others (e.g., Buylaert et al., 2011; Stevens et al., 2011; Buylaert et al., 2012; Lowick et al., 2012). Some exceptions were also reported by Reimann and Tsukamoto (2012) who found that the residual doses associated with the $50^{\circ} \mathrm{C}$ IRSL and pIRIR(150) signals were the same after a prolonged bleach, although the pIRIR signal has been shown to bleach more slowly than the $50^{\circ} \mathrm{C}$ IRSL signal.

In Fig. 5a, all published residual doses for the $\operatorname{pIRIR}(50,290), \operatorname{pIRIR}(50,225)$ and the $250^{\circ} \mathrm{C}$ METpIRIR signals are summarized for a range of different samples from different geographical regions and depositional environments. All the data are also summarized and referenced in Table S1. Large variation in the residual doses of the pIRIR signals can be seen in Fig. 5a. For the $\operatorname{pIRIR}(50,290)$ signal, the majority of the samples studied have residual doses lower than $\sim 35 \mathrm{~Gy}$, but there are 10 samples from Switzerland (Lowick et al., 2012) yielding high residual doses of between $\sim 39$ and $145 \mathrm{~Gy}$. Residual doses up to $\sim 60$ Gy were also reported for the pIRIR(50, 225) signal. Again, the highest values are all reported for the 10 waterlain sediments from Switzerland ranging between $\sim 13$ and 53 Gy (Lowick et al., 2012). Most of the rest of the samples have residual doses of less than $\sim 17$ Gy. The pIRIR $(50,225)$ signal, thus, appears to have smaller residual doses compared to the $\operatorname{pIRIR}(50$, 290) signal. We note that the residual doses reported in published papers (Table S1) were measured using different bleaching methods and a variety of durations, which could result in different residual doses. However, many of the largest residual doses reported were obtained from samples given the most extensive bleaches. For example, Lowick et al. (2012) bleached their samples using a $24 \mathrm{~h}$ exposure to a Sunlux Ambience UV lamp, and Stevens et al. (2011) bleached their samples using daylight for many days. In contrast, many of the samples with smaller residual doses were bleached for only a few hours (e.g., Li and Li, 2011a; Buylaert et al., 2012). We propose, therefore, that the observed variability in residual dose (Fig. 5) is due mainly to sample-to-sample variation, rather than different bleaching conditions used.

Large variation in the residual doses of the METpIRIR signals have also been observed, ranging from a few Gy to $\sim 30$ Gy (Table S1). We have plotted in Fig. 5b the residual doses of the MET-pIRIR signals for different samples from different regions as a function of IR stimulation temperature. Considerable variation in the residual doses for samples from different locations and at different IR stimulation temperatures can be seen. For all samples, the smallest residual doses (up to a few Gy) were obtained at an IR stimulation temperature of $50^{\circ} \mathrm{C}$, and the
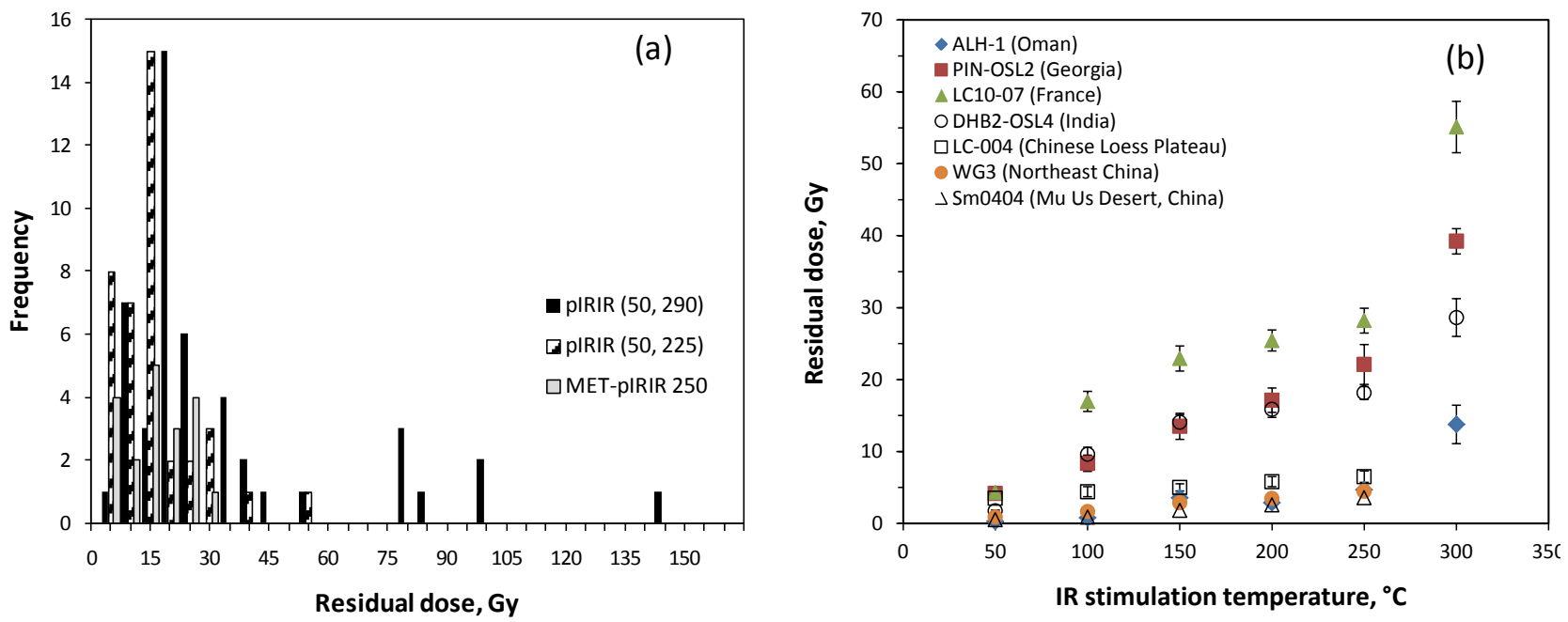

Fig. 5. (a) A summary of all published residual dose estimates for the pIRIR(50,290) and pIRIR(50, 225) signals for a range of different samples (Table S1). (b) Residual doses for the MET-pIRIR signals for different samples from different regions plotted against IR stimulation temperature. 
size of the residual dose and the extent of variation (in Gy) both increase with an increase in stimulation temperature (e.g., the residual doses range between $\sim 15$ and 55 Gy for the MET-pIRIR signal of 4 samples measured at $300^{\circ} \mathrm{C}$ ). From the results of Fig. 5, it is clear that the residual dose associated with the non-bleachable component is highly variable from sample to sample and from site to site. This highlights the importance of obtaining accurate and precise constraints on the residual dose, even for old samples, especially when stimulated at elevated temperatures.

A strong correlation between $D_{\mathrm{e}}$ and residual dose has also been reported by some authors where samples with higher $D_{\mathrm{e}}$ values tend to have higher residual doses (e.g., Sohbati et al. (2012) and Buylaert et al. (2012) and Schatz et al. (2012) for the pIRIR $(50,290)$ signal). They suggested that this is due to stronger (or more prolonged) sunlight exposure in nature in the past compared to what they have used in the laboratory to conduct their bleaching experiments (i.e., bleaching with a solar spectrum on a laboratory time scale did not result in a comparable residual reached in nature). It was, therefore, suggested that residual doses at $D_{\mathrm{e}}=0$ (obtained according to the plot of residual dose against $D_{\mathrm{e}}$; see Fig. 5B in Buylaert et al. 2012) should represent the true residual dose. To further investigate if this phenomena is generally applicable for samples from different regions and different ages (or $D_{\text {e), }}$, we have plotted in Fig. 6a all published residual dose estimates obtained for the $\operatorname{pIRIR}(50,290)$, $\operatorname{pIRIR}(50$, 225) and MET-pIRIR $250^{\circ} \mathrm{C}$ signals as a function of their residual-dose-corrected $D_{\mathrm{e}}$ values $\left(D_{\mathrm{e}}-\right.$ residual). It is noted that 5 samples from Lowick et al. (2012) are not shown in Fig. 6a; their pIRIR $(50,290)$ signals were saturated and no $D_{\mathrm{e}}$ values were obtained. From Fig. 6a, it appears that there is a positive correlation between the residual dose and residual-corrected $D_{\mathrm{e}}$ values for some samples, and that this correlation is site specific. For example, the residual dose of the 5 samples of Lowick et al. (2012) could range from $\sim 38$ to $\sim 80$ Gy with corresponding $D_{\mathrm{e}}$ values from $\sim 40$ to $\sim 500 \mathrm{~Gy}$ for the pIRIR $(50,290)$ signal. For the Romanian loess samples, however, the residual dose only increase from $\sim 11$ Gy to $\sim 33$ Gy with corresponding $D_{\mathrm{e}}$ values ranging from $\sim 50$ Gy to $\sim 1600$ Gy. Furthermore, residual doses ranging from a few Gy to over 50 Gy was also reported for modern samples (shown on the y-axis of Fig. 6a), suggesting that samples with small $D_{\mathrm{e}}$ values do not necessarily have small residual doses, and vice versa. This is further demonstrated in Fig. $\mathbf{6 b}$ where the ratio of the residual dose and the $D_{\mathrm{e}}$ value is plotted against the $D_{\mathrm{e}}$ value for each sample. It shows that the residual dose could be as high as $\sim 50-100 \%$ of the measured $D_{\mathrm{e}}$ value for very young samples with low $D_{\mathrm{e}}$ values, and that the proportion of residual dose relative to $D_{\mathrm{e}}$ decrease with an increase in $D_{\mathrm{e}}$. The 5 samples with $\operatorname{pIRIR}(50,290)$ values that deviate significantly from the general pattern are those obtained by Lowick et al. (2012). A residual dose to $D_{\mathrm{e}}$ ratio less than $5 \%$ cannot be guaranteed even for samples with a $D_{\mathrm{e}}$ as high as $\sim 500 \mathrm{~Gy}$. We, therefore, suggest that sunlight or SOL2 bleaching tests might be a convenient way to obtain a minimum residual dose estimate for samples specific to each study site, and that it should be routinely conducted, even for old samples.
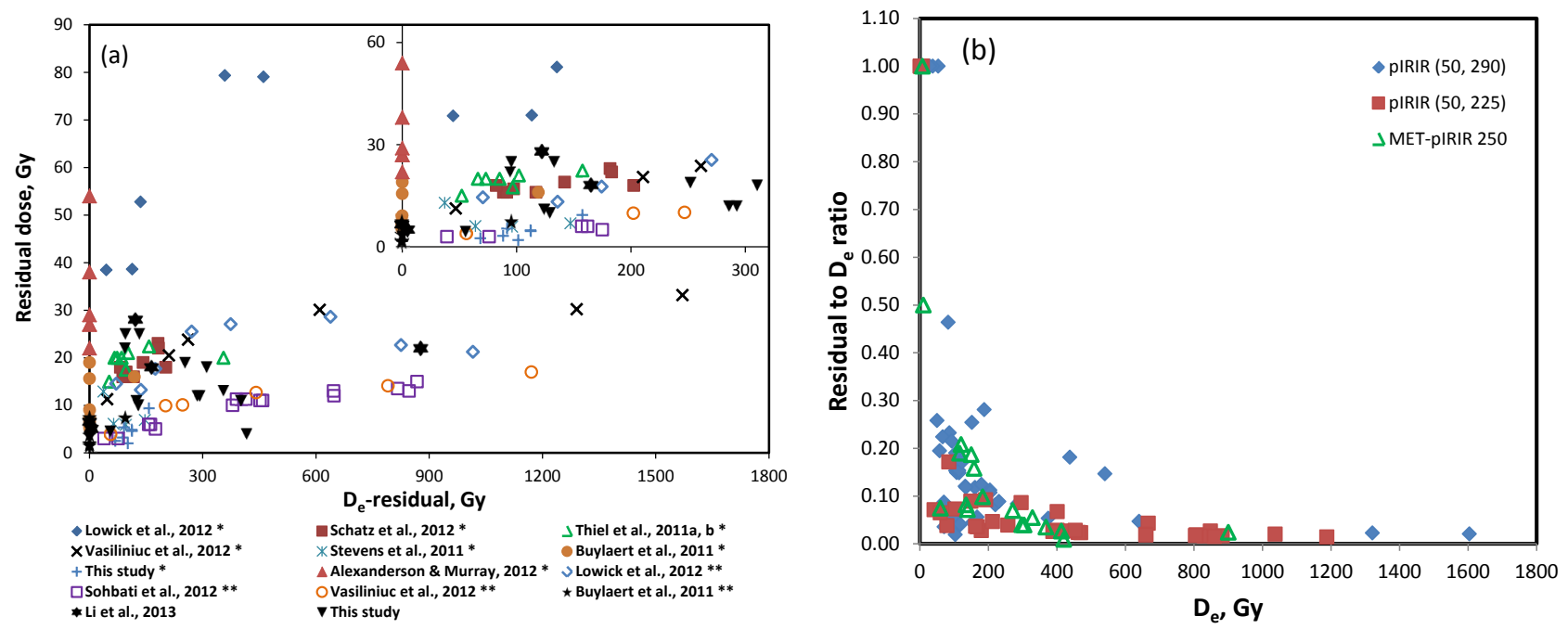

Fig. 6. (a) The relationship between residual-corrected $D_{e}$ values and residual doses for the pIRIR(50, 290), pIRIR(50, 225) and MET-pIRIR 250 ${ }^{\circ} \mathrm{C}$ signals of different samples (see Table S1 for original data). The inset shows the enlarged scale for $D_{e}$ values smaller than $320 \mathrm{~Gy}$. The pIRIR(50, 290) and pIRIR $(50,225)$ results are marked by * and ** following the legend of each study, respectively. The MET-pIRIR(250) results are not marked. (b) The residual dose to $D_{e}$ ratio plotted against the $D_{e}$ value for each sample presented in (a). 
As demonstrated by the data from previous studies, the residual dose appears to be a common phenomenon for pIRIR signals (Fig. 6a). The source of the residual signal is, however, still poorly understood, because of the difficulty to distinguish between the non-bleachable and thermally transferred signals. The correlation between residual dose and $D_{\mathrm{e}}$ observed for some samples (e.g., Sobhati et al., 2012; Buylaert et al., 2012) may indicate that thermal transfer might play an important role in the production of residual signals. However, such a relationship may also be explained as a result of the dose dependency of a non-bleachable signal with an increase in natural dose. This dose dependence of the residual signal has previously been reported by Li et al. (2013). For unheated sediments, the traps associated with the nonbleachable signal are expected to be in dose saturation due to the long geological history of the grains (e.g., millions of years). As a result, young samples should have the same residual dose as older samples, if the samples have the same proportion of non-bleachable and bleachable traps. However, this condition is not guaranteed for all the sediments. It is very likely that the nonbleachable traps of some grains could have been reset by heat before burial due to, for example natural fires, volcanic eruptions etc., which commonly occur in nature. After burial, these traps are then re-filled by exposure to naturally-occurring ionising radiation. If this is the case then older sediments will have a higher residual dose.

No matter which source the residual signal is from, it has to be corrected for appropriately for young samples and even for some old samples (Fig. 6a and $\mathbf{6 b}$ ). The most straightforward method is to subtract the residual dose obtained by directly bleaching the natural sample from the corresponding $D_{\mathrm{e}}$ values. This method will, however, result in underestimation, as demonstrated mathematically by Li et al. (2013). This problem can be overcome by applying an 'intensity-subtraction' method, proposed by Li et al. (2013), involving the construction of a dose response curve for the residual signal and then subtraction of the dose-dependent residual signal from the total signal. This method does not require information from modern analogues so it can be applied to the same sample that is dated. A drawback of this method is that it requires more aliquots and longer measurement time. An alternative way to deal with the residual dose problem is to establish a relationship between residual dose and $D_{\mathrm{e}}$ using a series of samples from the same study site, as proposed by Sobhati et al. (2012) and Buylaert et al. (2012), to calculate the residual dose using the intercept on the residual-dose axis and subtract this residual dose from the $D_{\mathrm{e}}$ of associated samples. This method can, however, only be applied to samples from the same site and requires that all the samples have the same luminescence behaviour and bleaching histories, and it is not applicable for the sites from which insufficient samples with different ages were available.

\section{SAR performance}

Whether a SAR protocol is appropriate for $D_{\mathrm{e}}$ measurement for a particular sample can be evaluated using several established tests, such as the recycling ratio test, degree of recuperation and a dose recovery test (Wintle and Murray, 2006). The first two tests can be obtained as part of the construction of the dose response curve, which involves measurement of a repeat dose at the end of the measurement sequence to obtain the recycling ratio, and measurement of a sensitivity-corrected zero dose that is then compared to the sensitivity-corrected natural dose to obtain an estimate of signal recuperation. The dose recovery test investigates the ability of the SAR protocol to recover a known dose given to a sample that has been optically bleached. For the IRSL and pIRIR measurements of feldspars, a similar SAR structure to quartz OSL has been used, and the same three tests adopted to evaluate their SAR performance (Wallinga et al., 2000).

\section{Recycling ratio and recuperation}

In a SAR protocol, Murray and Wintle (2000) suggested that any recycling ratio of between 0.90 and 1.10 is acceptable. Based on 183 aliquots from 29 samples, Buylaert et al. (2009) found an overall recycling ratio of $0.996 \pm 0.002$ when measuring the dose using the pI$\operatorname{RIR}(50,225)$ signal, suggesting that the test dose is monitoring the sensitivity change appropriately for their laboratory-irradiated samples. A similar result was also reported for the pIRIR(50, 290) (Buylaert et al., 2012) and MET-pIRIR signals (Li and Li, 2011a).

The effect of recuperation is usually expressed as a percentage ratio between the sensitivity-corrected zero dose signal and the sensitivity-corrected natural signal, and it was suggested that this value should not exceed 5\% (Murray and Wintle, 2000). For the pIRIR $(50,225)$ signal, an average recuperation value of $3.47 \pm 0.13 \%$ $(n=183)$ was obtained by Buylaert et al. (2009). These authors also reported recuperation of $<4 \%$ for the pI$\operatorname{RIR}(50,290)$ signal for the majority of their samples (Buylaert et al., 2012). For the MET-pIRIR signals, Li and Li (2011a) observed higher recuperation for the MET-pIRIR signals measured at higher temperatures. They found that the level of recuperation is also dependent on the size of the natural dose; younger samples tend to have higher recuperation because it is expressed as a fraction of the natural signal. For young samples, recuperation values for the $250^{\circ} \mathrm{C}$ MET-pIRIR signal are generally $<5 \%$, and the recuperation values for older samples and the lower-temperature MET-pIRIR signals are smaller. These studies suggest that recuperation of pIRIR signals are generally low and acceptable in the SAR protocols used.

\section{Preheat temperature dependence}

A preheat before OSL or IRSL measurement is required to remove any thermally unstable charge and to 
mimic any charge transfer that may have occurred in nature. A suitable preheat temperature should be chosen so that it is high enough to be able to remove all the unstable charge that may escape in nature and low enough to avoid depleting the main luminescence traps used for dating and that may cause significant sensitivity change. For the pIRIR methods, a higher preheat temperature could also remove more easy-to-fade components in the subsequent IRSL signals (e.g., Jain and Ankjærgaard, 2011). Whether the preheat temperature used in the protocol is suitable or not can be tested by investigating if there is any dependence of $D_{\mathrm{e}}$ upon preheat temperature, the so-called 'preheat plateau' test (Murray and Roberts, 1998; Murray and Wintle, 2000).

$\mathrm{Li}$ and $\mathrm{Li} \mathrm{(2011a)} \mathrm{first} \mathrm{tested} \mathrm{the} \mathrm{effect} \mathrm{of} \mathrm{preheat}$ temperature on the pIRIR signals using the MET-pIRIR procedure. They showed that, for their samples from northern China, there is no systematic dependence of $D_{\mathrm{e}}$ upon the preheat temperature ranging between 220 and $300^{\circ} \mathrm{C}$ for the MET-pIRIR signals measured at elevated temperatures $\left(>150^{\circ} \mathrm{C}\right)$. A slight decrease of $D_{\mathrm{e}}$ at higher preheat temperatures was, however, observed for the IRSL and MET-pIRIR signals measured at lower stimulation temperatures $\left(50\right.$ and $\left.100^{\circ} \mathrm{C}\right)$. Reimann et al. (2011) conducted a preheat plateau test for pIRIR signals measured at $180^{\circ} \mathrm{C}(\mathrm{pIRIR}(50,180))$ using a Holocene coastal sample from the Darss-Zingst peninsula. The measured $D_{\text {e }}$ values appear to decrease with an increase in preheat temperature for the $\operatorname{pIRIR}(50,180)$ signal. They also observed that a higher preheat temperature resulted in higher thermal transfer and recuperation. Roberts (2012) tested the effect of preheat temperature on the pIRIR signals using loess samples from Alaska. She reported a strong dependence of $D_{\mathrm{e}}$ with changes in preheat; $D_{\mathrm{e}}$ values increased significantly with preheat temperatures above $280^{\circ} \mathrm{C}$, and a plateau region was only observed between 250 and $280^{\circ} \mathrm{C}$. Based on dose recovery test results and comparisons with independent ages, Roberts (2012) concluded that a high preheat temperature $\left(>300^{\circ} \mathrm{C}\right)$ will result in significant overestimation of $D_{\mathrm{e}}$ for her samples. The results obtained using preheat temperatures of between 250 and $300^{\circ} \mathrm{C}$ gave reliable age estimates. She, thus, suggested that the preheat temperature is the primary driver of a change in $D_{\mathrm{e}}$ estimation rather than the pIRIR stimulation temperature. More studies are required to test whether this is a common phenomenon for different samples from different regions. These studies, however, suggest that a preheat temperature dependency of $D_{\mathrm{e}}$ estimates should be routinely conducted for all pIRIR methods. It is noted that one cannot use the $\operatorname{pIRIR}(50,290)$ signal when a lower preheat temperature $\left(<300^{\circ} \mathrm{C}\right)$ is used and this same caveat applies to the MET-pIRIR signal measured at $300^{\circ} \mathrm{C}$.

\section{Stimulation temperature dependence}

The pIRIR stimulation temperature appears to play a key role in $D_{\mathrm{e}}$ estimation, and it was demonstrated in
Figs. 1, 2 and 3 that the $\operatorname{pIRIR}(50,225)$ and $\operatorname{pIRIR}(50$, 290) signals may yield different results when measuring fading rates and estimating $D_{\mathrm{e}}$ values (Fig. 1-3) for the same samples. Apart from the pIRIR stimulation temperature, it was further argued that the stimulation temperature in the prior IR stimulation (T1) may also be an important factor ( $\mathrm{Li}$ and $\mathrm{Li}, 2011 \mathrm{a})$. $\mathrm{Li}$ and $\mathrm{Li}$ (2011a) suggested that an IR bleach at $50^{\circ} \mathrm{C}$ may be insufficient for removing all the easy-to-fade signals, and any remaining easy-to-fade signals will be subsequently sampled by the next post-IR measurement. This led them to propose the MET-pIRIR method in order to progressively remove the fading component (see section 3).

Thomsen et al. (2011) investigated the effect of prior IR stimulation temperature on thermal stability. The effect of prior IR stimulation temperature on $D_{\mathrm{e}}$ estimation was subsequently investigated by $\mathrm{Li}$ and $\mathrm{Li}(2012 \mathrm{~b}$ ) using samples from the Chinese Loess Plateau. They found that the $\operatorname{pIRIR}(50,290)$ signal may underestimate $D_{\mathrm{e}}$ for older samples with large natural doses ( $>500 \mathrm{~Gy})$, although it appears to yield reliable results for younger samples. They also found that such underestimation in the two-step pIRIR ages disappeared if the stimulation temperature of the prior-IR measurement was increased from $50^{\circ} \mathrm{C}$ to $200^{\circ} \mathrm{C}$, indicating that a high stimulation temperature of the prior-IR measurement can remove the fading component more effectively. Buylaert et al. (2012) subsequently tested the effect of the stimulation temperature in the two-step pIRIR procedure, and they found that varying the first stimulation temperature in the range 50 to $260^{\circ} \mathrm{C}$ has negligible effect on $D_{\mathrm{e}}$ for their samples. However, this could be due to the fact that the samples used for their study are relatively young $(<150 \mathrm{ka})$ and have relatively low $D_{\mathrm{e}}$ values $(<570 \mathrm{~Gy})$; the oldest sample (A19) investigated by Buylaertet al., (2012) has a $D_{\mathrm{e}}$ of $\sim 566 \mathrm{~Gy}$, which is close to the dose range where consistency were observed between the pIRIR $(50,290)$ and pIRIR(200, 290) ages ( $\mathrm{Li}$ and $\mathrm{Li}, 2012 \mathrm{~b})$. It is suggested that the effect of the stimulation temperature of the first IRSL measurement on the two-step pIRIR ages should be tested for older samples ( $>500 \mathrm{~Gy}$ ) to avoid insufficient removal of the easy-to-fade component by a single low temperature IR stimulation.

\section{Test dose dependence}

In the SAR protocol for pIRIR dating (Table 1), a test dose is applied to monitor and correct for sensitivity change that may occur between the natural and regenerative signals. It is prudent to use a test dose as small as possible to avoid any unwanted dose-dependent effects (e.g., sensitivity change) and also to save measurement time, and it also should not be too small to ensure adequate signal intensity. The effect of the size of the test dose on $D_{\mathrm{e}}$ estimation for pIRIR dating was first investigated by Qin and Zhou (2012). It was found that the measurement of the test dose signal is influenced by the thermally-transferred signals, which may affect estima- 
tion of $D_{\mathrm{e}}$ and fading rates. Based on this observation, Qin and Zhou (2012) suggested that a relatively large test dose $(50-80 \mathrm{~Gy})$ is preferable to minimise the effect of thermal transfer. It is noted that no high temperature clean-out was used between the different SAR cycles in Qin and Zhou (2012) that may complicate this interpretation. A contrary observation was, however, reported by Buylaert et al. (2012) who found no systematic change in $D_{\mathrm{e}}$ with a 3 to 4 fold change in the size of the test dose. Given the different experimental observations made for different samples, it appears that the degree of thermal transfer and sensitivity change induced by the irradiation and preheat used in test dose measurement may vary significantly from sample to sample. The choice of the size of test dose for $D_{\mathrm{e}}$ estimation should, thus, be tested and determined for each set of samples.

\section{Dose recovery test}

One critical assumption of the SAR protocol is that the test dose signal following the measurement of the natural signal accurately reflects the sensitivity of the natural signal. The validity of this assumption is usually tested using a dose recovery experiment (Murray and Roberts, 1998; Wallinga et al., 2000). This test involves giving a known laboratory dose to bleached aliquots. Such a given dose is then measured as an 'unknown' dose to test if the SAR protocol can reproduce the right answer. It is to be noted that a successful dose recovery test does not guarantee an accurate $D_{\mathrm{e}}$ estimation, but a failed dose recovery test does suggest that the $D_{\mathrm{e}}$ estimation is likely to be wrong. Buylaert et al. (2012) provided data that contradicts this general assumption. They conducted dose recovery tests using the IR(50) signal following two different preheat temperatures, 250 and $320^{\circ} \mathrm{C}$ and ob- tained measured/given dose ratios of $0.96 \pm 0.02(n=12)$ and $0.72 \pm 0.02(n=58)$, respectively. This is despite obtaining $D_{\mathrm{e}}$ estimates using both temperatures that are indistinguishable from each other. They concluded that a poor dose recovery test does not necessary predict inaccurate $D_{\mathrm{e}}$ estimation (Buylaert et al., 2012).

Dose recovery tests have been conducted to test the reliability of the pIRIR protocols in previous studies (see Table S2 for a summary of the data). In Fig. 7 we have summarised the dose recovery test results for the different pIRIR protocols: pIRIR $(50,225)(n=29), \operatorname{pIRIR}(50,290)$ $(n=47)$ and MET-pIRIR(250) $(n=12)$. Note that each measured to given dose ratio represents an average obtained for several aliquots from the same sample and that the number of aliquots varies between the different studies. Fig. 7a presents a histogram of the different measured to given dose ratios obtained for the three different pIRIR protocols. The ratios obtained for $\operatorname{pIRIR}(50,225)$ range between 0.9 and 1.3 for 28 samples except one sample showing a much higher measured to given dose ratio of $2.04 \pm 0.23$; this outlier was obtained for a given dose of 1200 Gy (Vasiliniuc et al., 2012), similar to a natural dose from the same set of samples that was shown to be close to, or in, saturation. We ignore this value for our statisitcal analysis since this given dose is close to the saturation dose level. The measured to given dose ratios obtained for 48 samples measured using the pIRIR(50, 290) signal, ranged between 0.83 and 1.57. Again, there is one sample with a much higher ratio of 1.98 , but a large standard error of \pm 0.60 (Roberts, 2012); the given dose for this sample was $\sim 300 \mathrm{~Gy}$. Measured to given dose ratios using the MET-pIRIR $250^{\circ} \mathrm{C}$ signal has only been reported for 12 samples, and the ratios fall between 0.92 and 1.13. The overall average values of the dose
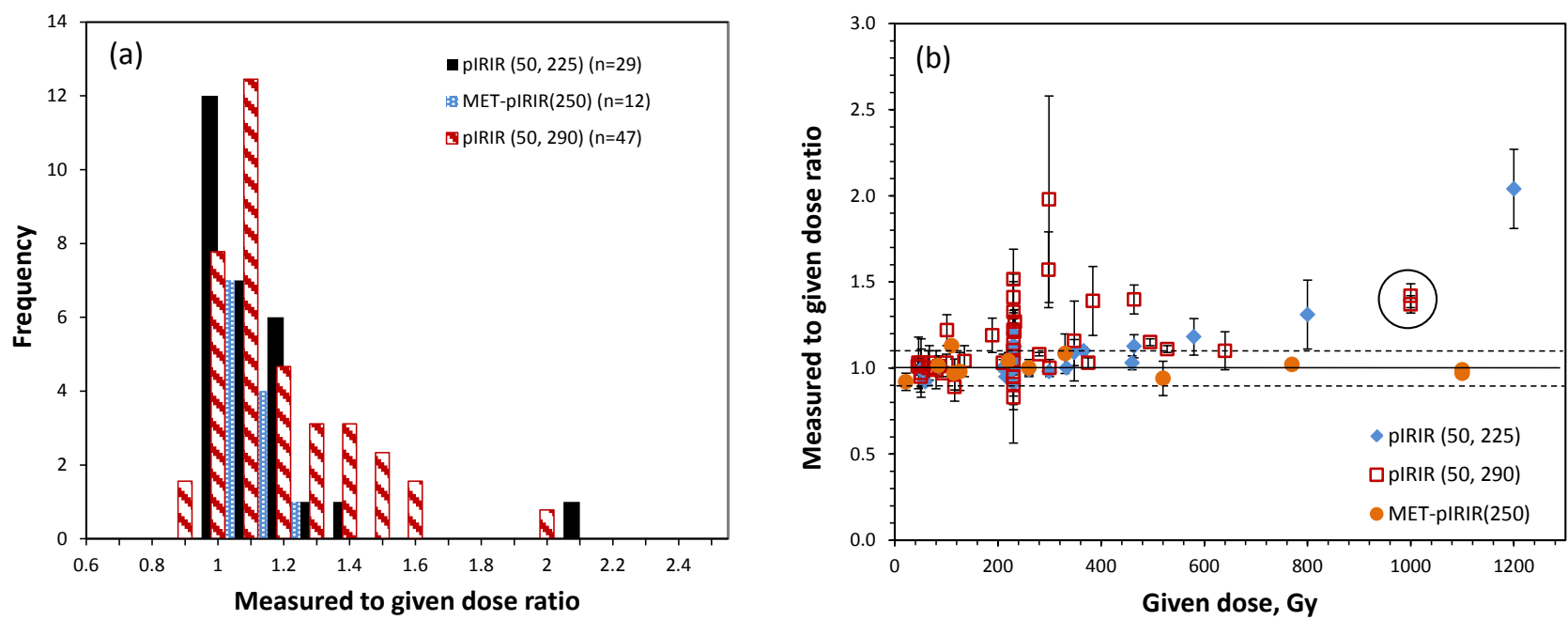

Fig. 7. (a) Dose recovery results shown as a histogram for different pIRIR protocols (pIRIR(50,225), pIRIR(50, 290) and MET-pIRIR(250))(see Table $S 1$ for original data). (b) The measured to given dose ratios plotted against the given dose for the same data presented in (a). Each data point represents the average value of several aliquots from the same sample. The data points from Stevens et al. (2011) obtained for samples that were bleached behind window glass are circled. 
recovery ratios for $\operatorname{pIRIR}(50,225)$, $\operatorname{pIRIR}(50,290)$ and MET-pIRIR(250) are $1.04 \pm 0.01, \quad 1.13 \pm 0.03$ and $1.00 \pm 0.02$, respectively; these averages do not include the two high outliers or those reported by Stevens et al. (2011) that were bleached behind window glass.

In Fig. $7 \mathbf{b}$, the measured to given dose ratios are plotted against the given dose for all the samples summarised in Table S2. For the pIRIR(50, 225) signal, the recovered dose ratios are all consistent with $1.0 \pm 0.1$ at $1 \sigma$, except two data points obtained at 800 and 1200 Gy using the loess samples from Romania that are thought to be close to saturation (Vasiliniuc et al., 2012). This suggests that the SAR protocol is suitable when measuring the pI$\operatorname{RIR}(50,225)$ signal for doses smaller than $600 \mathrm{~Gy}$ (i.e., the highest given dose for which a ratio consistent with unity was obtained).

A much larger number of samples were measured using the $\operatorname{pIRIR}(50,290)$ methods $(n=47)$. Thirty-three of the 47 samples gave measured to given dose ratios consistent with unity at $2 \sigma$. All, but one of the samples for which the given dose was $<200$ Gy was consistent with unity, but for doses $>200$ Gy the pattern was more inconsistent, but there do not appear to be a relationship between given dose and measured to given dose ratio (Fig. 7b). Those values circled in Fig. 7b represent the samples that were bleached behind window glass and the given dose of $1000 \mathrm{~Gy}$ are close to, or in, saturation. For the MET-pIRIR $250^{\circ} \mathrm{C}$ signal, most of the measured to given dose ratios are consistent with unity at $1 \sigma$ for given doses ranging from 20 to $1100 \mathrm{~Gy}$. Since there is only a small number of dose recovery tests investigated using the MET-pIRIR method, and, more importantly, no direct comparison of the MET-pIRIR and two-step pIRIR methods in the behaviour using the same set of samples, we cannot comment on the differences in the dose recovery test results. More systematic and direct comparisons of the different methods using the same samples are required.

\section{Dose response curve}

The dose response curve (DRC) determines the dose range (and, thus, age range) that can be measured for any given sample. The DRCs of IRSL and pIRIR signals are usually described by a single saturating exponential function (Thomsen et al., 2008; Li and Li, 2011a):

$$
I=I_{0}\left(1-\exp \left(-\frac{D}{D_{0}}\right)\right)
$$

where $I$ is the sensitivity-corrected signal intensity, $D$ is the regenerative dose, $D_{0}$ is the characteristic saturation dose, and $I_{0}$ is the maximum intensity at infinite dose $(D \rightarrow \infty)$, or a double saturating exponential function (Buylaert et al., 2012). The shape of the DRC and its saturation level are mainly controlled by the characteristic saturation dose $D_{0}$. A larger $D_{0}$ value indicates that the signal intensity will keep increasing at higher doses.
Wintle and Murray (2006) suggested that a value of $2 D_{0}$ could be taken as an conservative upper limit for dose measurement for quartz, but $\mathrm{Li}$ and $\mathrm{Li}$ (2012a) found that a reliable $D_{\mathrm{e}}$ beyond $2 D_{0}$ can also be obtained using MET-pIRIR signal from Chinese loess samples - e.g., $D_{\text {e }}$ values up to 1000 Gy were obtained using METpIRIR(250) signal even though the corresponding $2 D_{0}$ value is $600-700 \mathrm{~Gy}$ - but a loss of precision was inevitable ( $\mathrm{Li}$ and $\mathrm{Li}, 2012 \mathrm{a})$.

The shapes of the DRCs for the IRSL and pIRIR signals were compared in a few studies (e.g., Buylaert et al., 2009; Vasiliniuc et al., 2012; Thiel et al., 2011a; 2011b; Thomsen et al., 2011; Andersen et al., 2012). Buylaert et al. (2009) first compared the DRCs of $50^{\circ} \mathrm{C}$ IRSL and $\operatorname{pIRIR}(50,225)$ signals for a sample from Denmark, and found that there is no difference in the DRCs up to 2000 Gy. A similar observation was reported by Sohbati et al. (2012). However, different shapes were observed between the $50^{\circ} \mathrm{C}$ IRSL and $\operatorname{pIRIR}(50,225)$ signals for K-feldspar from Romanian loess (Vasiliniuc et al., 2012). They also observed lower sensitivity-corrected signal intensities and an earlier dose saturation for the $\operatorname{pIRIR}(50$, 225) signal. For the pIRIR $(50,290)$ method, Thiel et al. (2011a) first compared the DRCs for both the $50^{\circ} \mathrm{C}$ IRSL and $\operatorname{pIRIR}(50,290)$ signals for their loess samples from Austria, and found indistinguishable DRCs for the two signals. However, using Japanese loess samples, Thiel et al. (2011b) subsequently reported an earlier saturation in the DRC of the pIRIR $(50,290)$ signal compared to that of the $50^{\circ} \mathrm{C}$ IRSL. Similar results were also reported for pIRIR $(50,300)$ signals from Romanian loess (Vasiliniuc et al., 2012) and pIRIR $(50,245)$ signals from a shallow marine Eemian sample from Denmark (Thomsen et al., 2011). Different DRCs of MET-pIRIR signals were also reported (Li and Li, 2011a; Fu et al., 2012a; Li and Li, 2012a). Based on eolian samples from northern China, Li and $\mathrm{Li}$ (2011a, 2012a) found that the shapes of the DRCs differ according to stimulation temperature for the METpIRIR signals, with the $50^{\circ} \mathrm{C}$ IRSL dose response growing to the highest doses. The DRCs are similar for the signals measured at 50,100 and $150^{\circ} \mathrm{C}$, while an earlier saturation was observed for the signals measured at 200 and $250^{\circ} \mathrm{C}$.

To provide an example of systematic comparison between the DRCs for different IRSL and pIRIR signals at different temperatures using the same sample, we measured the DRCs using different pIRIR methods using 6 aliquots of an aeolian sample (Sm8) from the Mu Us Desert, central China. It is noted that the behaviour of this sample may not necessarily represent the K-feldspar from other regions. Fig. 8a shows the DRCs using the two-step pIRIR method with various combinations of stimulation temperatures and preheat temperatures (shown in the legend). The $50^{\circ} \mathrm{C}$ IRSL signal, measured using the pI$\operatorname{RIR}(50,290)$ method with a preheat at $320^{\circ} \mathrm{C}$ for $60 \mathrm{~s}$, shows the highest $D_{0}$ value of $575 \pm 36 \mathrm{~Gy}$. The pI$\operatorname{RIR}(50,290)$ signal grows indistinguishably from the 
$50^{\circ} \mathrm{C}$ IRSL signal up to $\sim 500 \mathrm{~Gy}$, but gets depressed and saturated earlier at higher dose. The influence of the prior-IR stimulation temperature on the DRC was also investigated using different prior stimulation temperatures (T1), at 100,150 and $200^{\circ} \mathrm{C}$, together with the same pIRIR stimulation temperature at $250^{\circ} \mathrm{C}$ and preheat at $300^{\circ} \mathrm{C}$ for $60 \mathrm{~s}$ (Fig. 8a). It is shown that different prior stimulation temperature (T1) results in a different sensitivity-corrected intensity, indicating a different extent of changes in response from the natural or regenerative step to the test dose measurement (Chen et al., 2001; Wintle and Murray, 2006). Increasing the prior stimulation temperature also results in an earlier saturation of the signals. The saturation levels of the DRCs in Fig. 8a can be demonstrated more clearly when all the DRCs are nor- malised to a saturation value of 1 (Fig. 8b). This result indicates that, although increasing the prior stimulation temperature in the pIRIR procedure may yield a more stable signal ( $\mathrm{Li}$ and $\mathrm{Li}, 2012 \mathrm{~b}$ ), it will also result in an earlier saturation of the pIRIR signal, which will limit the dating range of the pIRIR method.

The MET-pIRIR method is actually a simple combination of multiple pIRIR procedures with different prior IR stimulation temperatures, which are achievable on a single aliquot. Fig. 8c shows the DRCs of the METpIRIR signals at different IR temperatures obtained from a single aliquot of the same sample Sm8, and Fig. 8d shows the same set of DRCs but are normalised to a saturation value of 1 . As expected, different sensitivitycorrected DRCs was observed for different IRSL and
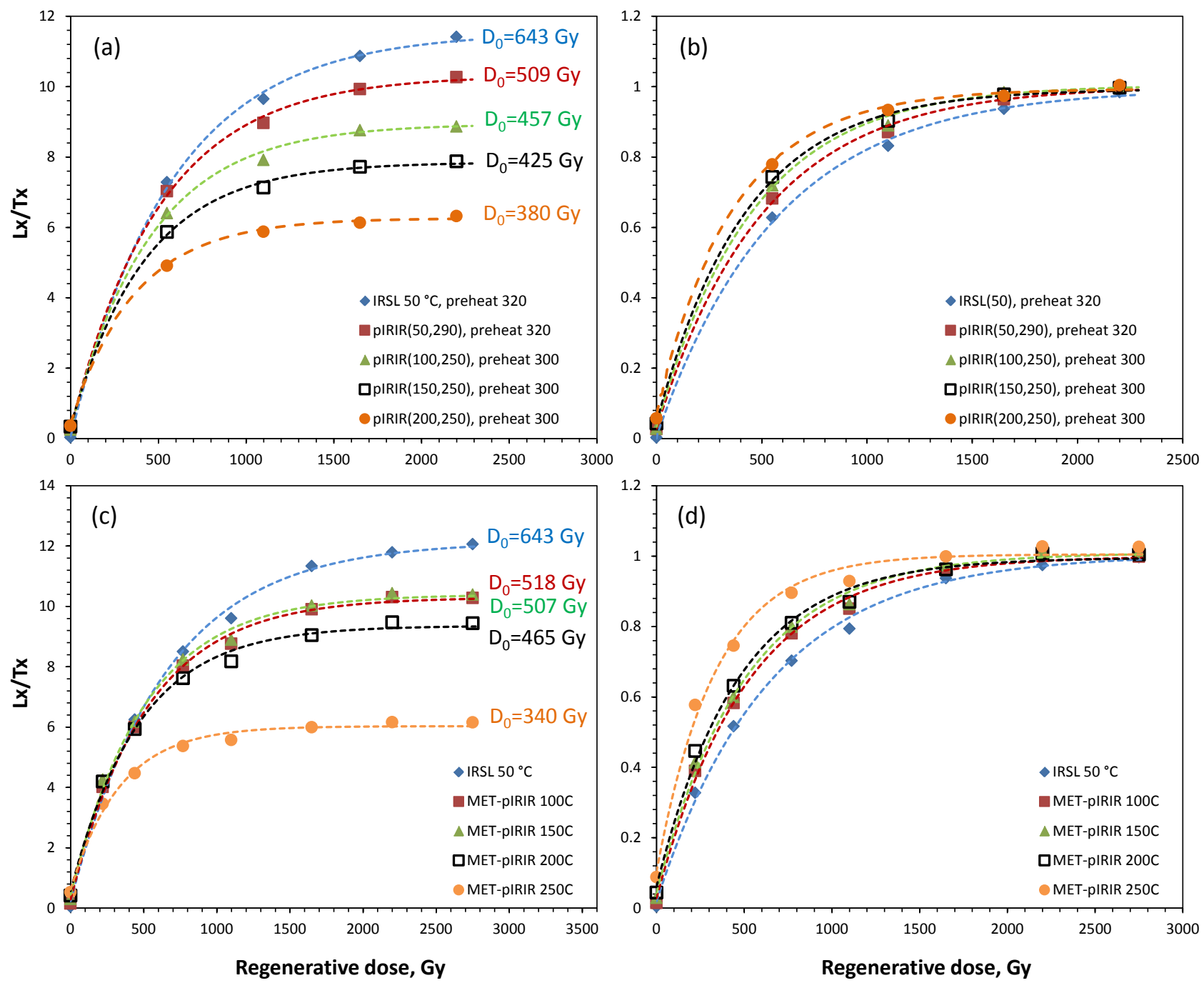

Fig. 8. (a) The DRCs of sample Sm8 obtained using a range of different two-step pIRIR protocols (measurement conditions shown in legend). (b) The same data sets as (a) but all the curves were normalised to a saturation value of 1. (c) The DRCs of sample Sm8 obtained using the MET-pIRIR method with a preheat of $300^{\circ} \mathrm{C}$. (d) The same data sets as (c) but all the curves were normalised to a saturation value of 1 . The dashed lines are the best-fit curves using a single exponential saturating function. The values of the characteristic saturation dose $\left(D_{0}\right)$ obtained for each $D R C$ are shown next to each curve in (a) and (c). 
MET-pIRIR signals. The $50^{\circ} \mathrm{C}$ IRSL signal yielded the highest sensitivity-corrected intensity and the highest saturation dose $\left(D_{0}=643 \pm 37 \mathrm{~Gy}\right)$. The DRCs for the 100 and $150^{\circ} \mathrm{C}$ signals are indistinguishable and have a similar $D_{0}$ value of $\sim 510 \mathrm{~Gy}$. The 200 and $250^{\circ} \mathrm{C}$ signals have lower intensities and lower $D_{0}$ values of 465 and 340 Gy, respectively. The results of the MET-pIRIR signals shown in Fig. 8c are very similar to the results of the pIRIR methods with different prior stimulation temperatures shown in Fig. 8a.This suggests that the shape and characteristic saturation dose of the DRCs of pIRIR signals is mainly determined by the prior stimulation temperature - a higher prior stimulation temperature will result in earlier saturation of the DRC.

According to the results of Fig. 8, it appears that the pIRIR method with an elevated prior IR stimulation temperature and the MET-pIRIR method may have an upper limit of dose determination at 700-800 Gy for the samples investigated if a $D_{\mathrm{e}}$ equal to $2 D_{0}$ is considered a conservative upper limit (Wintle and Murray, 2006; but see Galbraith and Roberts, 2012). However, variable saturation levels of the pIRIR signals for different samples from different regions of the world are possible. For example, a much higher $D_{0}$ value of $\sim 750 \mathrm{~Gy}$ was observed for the $\operatorname{pIRIR}(50,245)$ signal for a shallow marine Eemian sample from Denmark (Thomsen et al., 2011). Stevens et al. (2011) reported much lower $D_{0}$ values ( $<200$ Gy) using the pIRIR $(50,290)$ method for their loess samples from the Carpathian Basin in Europe, but the maximum dose given in their DRC is $\sim 400 \mathrm{~Gy}$, which limits the reliability of determining the true saturation dose level. Gliganic et al. (2012) obtained a $D_{0}$ value of $\sim 350$ Gy using the pIRIR $(50,225)$ method for their archaeological samples from Tanzania. Kars et al. (2012) obtained $D_{0}$ values of $\sim 400-500$ Gy using the pIRIR(100, 230) method for sediments from Netherlands.

In conclusion, the dating limit of the pIRIR method may be highly variable from sample to sample and region to region but the saturation dose level is highly dependent on the experimental condition used (e.g., prior IR stimulation temperature and the pIRIR stimulation temperature).

\section{AGE COMPARISON WITH INDEPENDENT AGES}

Although demonstrating that the SAR protocol performs reliably, using such tests as the recycling ratio, recuperation, preheat plateau, anomalous fading and dose recovery tests, the most important test of the reliability of any dating technique is whether it can yield consistent results when compared with ages for the same sample or context obtained using an independent dating technique. We provided in Table $\mathbf{S 1}$ the independent ages (i.e., 'expected age') for all published pIRIR ages where such ages were reported. The majority of samples for which independent ages were available range in age from 0 to $400 \mathrm{ka}$, except for one sample of Japanese loess (Tg22) for which a quartz OSL age $507 \pm 41 \mathrm{ka}$ and a fission track age of $660 \pm 40 \mathrm{ka}$ is known (Watanuki et al., 2005). Independent age control for the rest of the samples came from predominantly quartz OSL, but also from radiocarbon, fission track, tephra chronology and also stratigraphic correlation and paleomagnetism. We did not attempt to assess the quality of the independent ages for each of the samples, but rather assumed that the reliability of the independent ages was verified by the respective authors of each study.

Fig. 9 shows the fading-uncorrected pIRIR ages compared to independent ages for the three pIRIR methods that have been tested most extensively; $\operatorname{pIRIR}(50,225)$ (Fig. 9a and 9b), pIRIR(50, 290) (Fig. 9c and 9d) and MET-pIRIR $250^{\circ} \mathrm{C}$ (Fig. 9e and 9f). We also show as open symbols in Fig. 9a and 9b the fading-corrected pIRIR $(50,225)$ ages for the same samples. We have done this to reflect the current trend to correct the $\operatorname{pIRIR}(50$, $225)$ ages, but not the pIRIR $(50,290)$ ages for fading (see discussion above). The figures in the left-hand column show the entire age range, whereas those in the righthand column only show the samples younger than $100 \mathrm{ka}$ for clarity. We have also summarised in Table 2 the percentage of samples that have pIRIR ages consistent with their independent ages at 1 and $2 \sigma$. Since a primary purpose of the development of the pIRIR dating procedure is to extend the dating range to older samples $(>100 \mathrm{ka})$, we have divided the samples into two groups; one group is for samples older than $100 \mathrm{ka}$, and the other is from samples with ages between 20 and $100 \mathrm{ka}$. It is noted that in Table 2 we purposely ignored those samples

Table 2. The fraction of the samples that have pIRIR ages that are consistent with their independent ages for different methods. The number of samples (n) summarised for each method is shown.

\begin{tabular}{|c|c|c|c|c|c|c|}
\hline \multirow{2}{*}{ Method } & \multicolumn{2}{|c|}{ 20-100 ka } & \multicolumn{2}{|c|}{$>100 \mathrm{ka}$} & \multicolumn{2}{|c|}{$>20 \mathrm{ka}$} \\
\hline & $1 \sigma$ & $2 \sigma$ & $1 \sigma$ & $2 \sigma$ & $1 \sigma$ & $2 \sigma$ \\
\hline $\mathrm{pIRIR}(50,225), \mathrm{n}=38$ (Fading uncorrected) & $57 \%$ & $86 \%$ & $21 \%$ & $38 \%$ & $34 \%$ & $55 \%$ \\
\hline $\mathrm{pIRIR}(50,225), \mathrm{n}=38$ (Fading corrected) & $57 \%$ & $64 \%$ & $33 \%$ & $63 \%$ & $42 \%$ & $63 \%$ \\
\hline $\operatorname{pIRIR}(50,290), n=95$ & $57 \%$ & $81 \%$ & $41 \%$ & $73 \%$ & $51 \%$ & $78 \%$ \\
\hline MET-pIRIR 250, $n=30$ & $76 \%$ & $94 \%$ & $77 \%$ & $100 \%$ & $77 \%$ & $97 \%$ \\
\hline All methods, $n=197$ & $61 \%$ & $85 \%$ & $41 \%$ & $64 \%$ & $51 \%$ & $74 \%$ \\
\hline
\end{tabular}



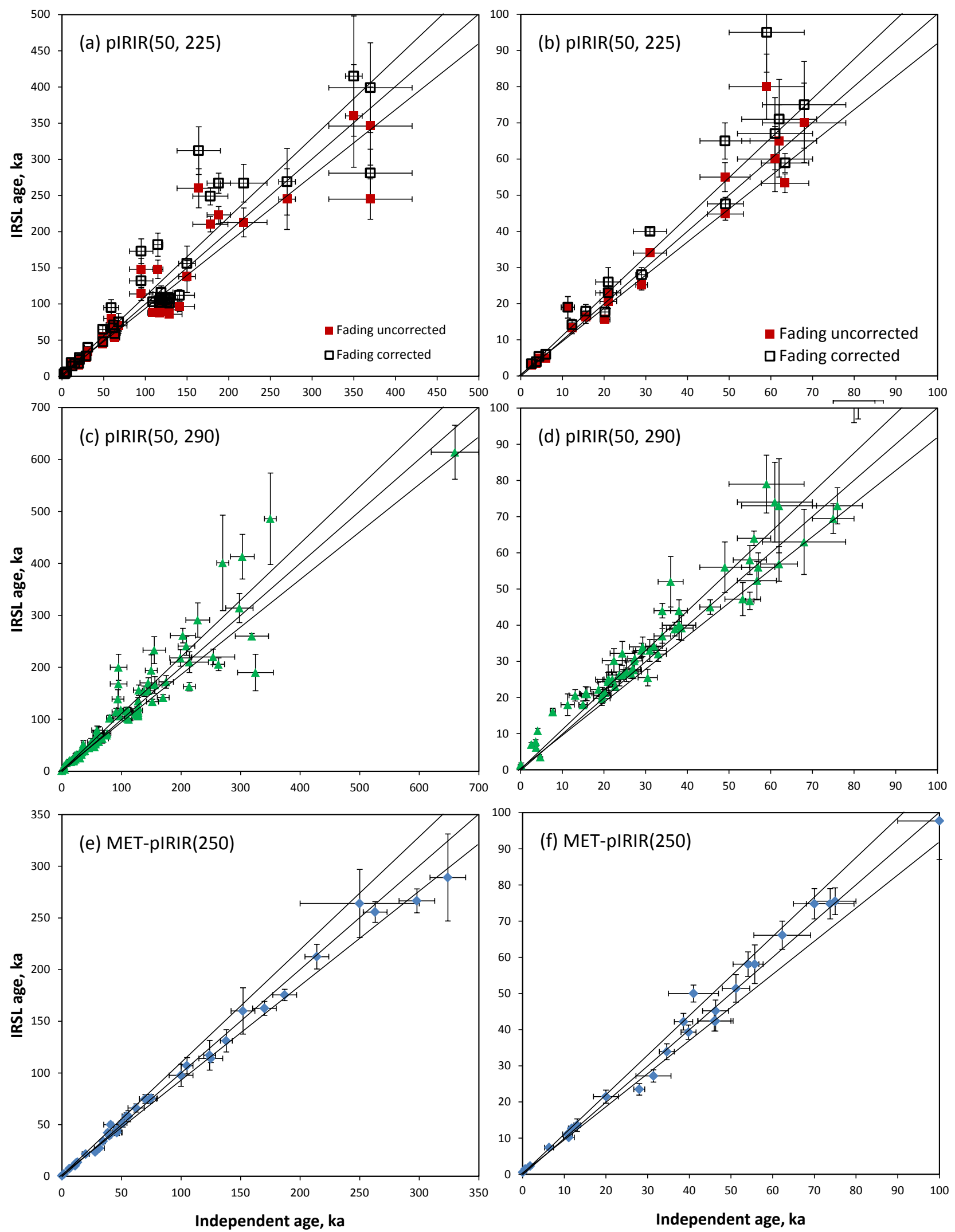

Fig. 9. Comparisons of independently obtained ages and the pIRIR ages for samples summarized in Table S1 obtained using (a) the pIRIR(50, 225) signal (fading corrected and uncorrected ages), (c) the pIRIR(50, 290) signal, and (e) the MET-pIRIR $250^{\circ} \mathrm{C}$ signal. (b), (d) and (f) show the same data sets as (a), (c) and (e), respectively, but only for younger samples on an enlarged scale. 
younger than $20 \mathrm{ka}$ to avoid significant influence on the statistics from issues associated with the measurement and subtraction of the residual dose for young samples.

There are 47 samples with independent ages that were measured using the $\operatorname{pIRIR}(50,225)$ method; 45 are shown in Fig. 9a and 2 samples, reported by Lowick et al. (2012), gave minimum ages that were excluded from this analysis as these were in, or close to, saturation. Of the 45 samples, 7 gave ages $<20 \mathrm{ka}, 14$ are between 20 and $100 \mathrm{ka}$ old, and 24 samples gave ages older than $100 \mathrm{ka}$ (Table S1). All 45 ages (fading-corrected and fading-uncorrected) are plotted against their respective independent age estimates in Fig. 9a and 9b. Taking into account all 45 samples, $58 \%$ of the fading-uncorrected $\operatorname{pIRIR}(50,225)$ ages, and $64 \%$ of the fading-corrected ages, are consistent with their independent ages at $2 \sigma$ (Table 2; Fig. 9b). For those samples with ages between 20 and $100 \mathrm{ka}(n=14), 86 \%$ are consistent at $2 \sigma$, but this decreases to $64 \%$ when the ages are corrected for fading. All the samples with fading-corrected ages that are inconsistent with their independent ages at $2 \sigma$ are those reported in Lowick et al. (2012) and these consistently overestimate their known ages. These samples had a residual dose subtracted prior to calculation of the ages, but since these ages are for waterlain sediments, inhomogeneous bleaching of the pIRIR signal may have led to age overestimation. If we ignore the 5 samples from Switzerland (Lowick et al., 2012), all but one sample (i.e., 8 out of 9) have fading-uncorrected ages consistent with the expected ages, and all samples $(n=9)$ have fadingcorrected ages consistent with the expected ages. Accordingly, there is no clear advantage of applying a fadingcorrection for the $\operatorname{pIRIR}(50,225)$ signal for the samples in this age group (20-100 ka).

For those samples with ages $>100 \mathrm{ka}(n=24), 38 \%$ (uncorrected) or 63\% (fading-corrected) are consistent with their independent ages at $2 \sigma$ (Fig. 9a). Fading correction appears to improve the consistency between the pIRIR ages and the expected ages for these samples, but we reserve our judgment on the validity of the fadingcorrected ages because of the limitation of the correction method to older samples (Huntley and Lamothe, 2001). The majority of the samples with fading-uncorrected ages inconsistent with their independent ages at $2 \sigma$ are those reported by Buylaert et al. (2012) for coastal sediment samples from Denmark and Russia. The coastal sand samples from Denmark with independent ages of $\sim 110$ 130 ka gave fading-uncorrected pIRIR ages that are consistently underestimated, whereas the coastal sediment samples from Russia with independent ages of between 115 and $218 \mathrm{ka}$ gave pIRIR ages that appear to either underestimate $(n=6)$ or overestimate $(n=3)$ their known ages. So, on average, there is no systematic over- or under-estimation of the fading-uncorrected pIRIR ages relative to their known ages and no average trend with age can be observed; the results are most likely sampledependent.
There are 121 samples with independent ages that were measured using the pIRIR(50, 290) method; 116 of these are shown in Fig. 9c and 5 samples, all reported by Lowick et al. (2012), were omitted because they were reported as minimum ages without error estimates and had signals that were in, or close to, saturation. Of the 116 samples, 23 gave expected ages $<20 \mathrm{ka}, 52$ fell between 20 and $100 \mathrm{ka}$, and 41 samples gave ages older than $100 \mathrm{ka}$ (Table S1). Whether or not a residual-dose subtraction was applied and how this residual dose was determined and subtracted varied among the different studies (see each study for relevant information). We have plotted here the final best-estimate ages reported in each study. Taking into account all 116 samples, $66 \%$ of the samples gave $\operatorname{pIRIR}(50,290)$ ages consistent with their independent ages at $2 \sigma$ (Table 2; Fig. 9b); this increase significantly to $77 \%$ if we omit the 25 samples with ages $<20 \mathrm{ka}$. These samples were not corrected for residual doses since many of these were used to obtain an estimate of the residual dose. For those samples with ages between 20 and $100 \mathrm{ka}(n=52), 81 \%$ are consistent at $2 \sigma$; the $19 \%(n=10)$ of samples with inconsistent ages all (except for one sample) have pIRIR ages that overestimate their known age. These samples come from a range of different geographical areas, including Egypt, Tunisia, Japan and Europe and represent different depositional environments, including coastal sand, aeolian dunes, loess and waterlain sediment. Six of these samples, from Thiel et al. (2011b; 2012) and Stevens et al. (2011), had not been corrected for any residual dose prior to pIRIR age determination. Residual doses of up to $20 \mathrm{~Gy}$ were observed for the Japanese samples (Thiel et al., 2011b). We note that if we subtract a residual dose of $20 \mathrm{~Gy}$ from their $D_{\mathrm{e}}$ values, the pIRIR ages are consistent with the expected ages for these samples. Age overestimation is also removed after subtracting the residual dose (32.8 Gy) measured for the sample of Stevens et al. (2011). For the two waterlain samples from Switzerland (Lowick et al., 2012), age overestimation was observed even after subtraction of the residual doses, but this could be due to insufficient bleaching prior to deposition. We cannot assess the reason for age overestimation of the sample from Egypt (Buylaert et al., 2012), because residual dose was not reported for this sample.

For those samples with ages $>100 \mathrm{ka}(n=41), 73 \%$ are consistent at $2 \sigma$. Eight of the 11 samples that are inconsistent have pIRIR ages that are underestimated relative to their known ages and only three are overestimated. This is in contrast to the ages obtained for samples between 20 and $100 \mathrm{ka}$. So, like the pIRIR(50,225) ages, there does not appear to be a systematic trend and the differences are probably sample dependent, but for younger samples (between 20 and $100 \mathrm{ka}$ ) it appears that estimation of an accurate and site-specific residual dose is critical. For the older samples (>100 ka), a small amount of fading, consistent with the average fading rate of $\sim 1.1 \%$ /decade (Fig. 2), may be more important than the 
residual dose. In other words, these two factors may work against each other, depending on the age of the sample and the relative size of the residual dose and the fading rate. Other effects, such as thermal stability, preheat temperature dependence, test dose dependence and sensitivity correction (see section 4) may also contribute to the spread in ages.

There are 38 samples with independent ages that were measured using the MET-pIRIR $250^{\circ} \mathrm{C}$ signal; ages for all 38 samples are presented in Fig. 9e. The MET-pIRIR method has been tested primarily for aeolian samples from northern China ( $\mathrm{Li}$ and $\mathrm{Li}, 2011 \mathrm{a}, 2012 \mathrm{a}$; Fu et al., 2012a) (see Table S1). Of the 38 samples, 8 gave ages $<20 \mathrm{ka}, 17$ are between 20 and $100 \mathrm{ka}$ old, and $13 \mathrm{sam}-$ ples gave ages older than $100 \mathrm{ka}$ (Table S1). No fading correction was applied to any of the ages and measured residual doses were subtracted from each sample $D_{\mathrm{e}}$ value prior to age calculation. Taking into account all 38 samples, $95 \%$ of the samples gave ages consistent with their independent ages at $2 \sigma$ (Table 2; Fig. 9e). There is no significant difference in the number of samples that are consistent with their independent ages for those samples that are between 20 and $100 \mathrm{ka}(94 \%$ at $2 \sigma$; Fig. 9f) and those older than $100 \mathrm{ka}(100 \%$ at $2 \sigma)$. The method appears to be reliable for most of the samples from this region and for samples as old as $\sim 300 \mathrm{ka}$. However, since most of these data are limited to samples from northern China that are expected to have similar luminescence behaviors, more studies from other regions of the world are required to test the broader applicability of the METpIRIR method.

Fig. 10a and 10b summarise all the feldspar IRSL ages presented in Fig. 9 together with those that utilised slightly different pIRIR approaches (see legend in Fig. 10a). It demonstrates that regardless of which pIRIR method is used, excellent agreement is obtained between the fading-uncorrected pIRIR ages and their independent ages for the samples between 20 and $100 \mathrm{ka}$ (Fig. 10b); this consistent pattern falls apart for older samples (>100 ka) (Fig. 10a). For samples between 20 to $100 \mathrm{ka}$, $85 \%$ of the samples are consistent with their independent ages at $2 \sigma$ (Table 2). For the older samples (>100 ka), only $64 \%$ of the samples yielded ages consistent with their independent ages at $2 \sigma$, and both over- or underestimated ages are obtained for the rest of the samples (Fig. 10a).

In summary, the dating results using various pIRIR protocols are sensitive to the procedure and experimental conditions chosen. All the different variations of the pIRIR methods, however, appear to yield reliable ages for relatively young samples (20-100 ka), but the reliability for dating older samples is not guaranteed and both under- and overestimation may be obtained.

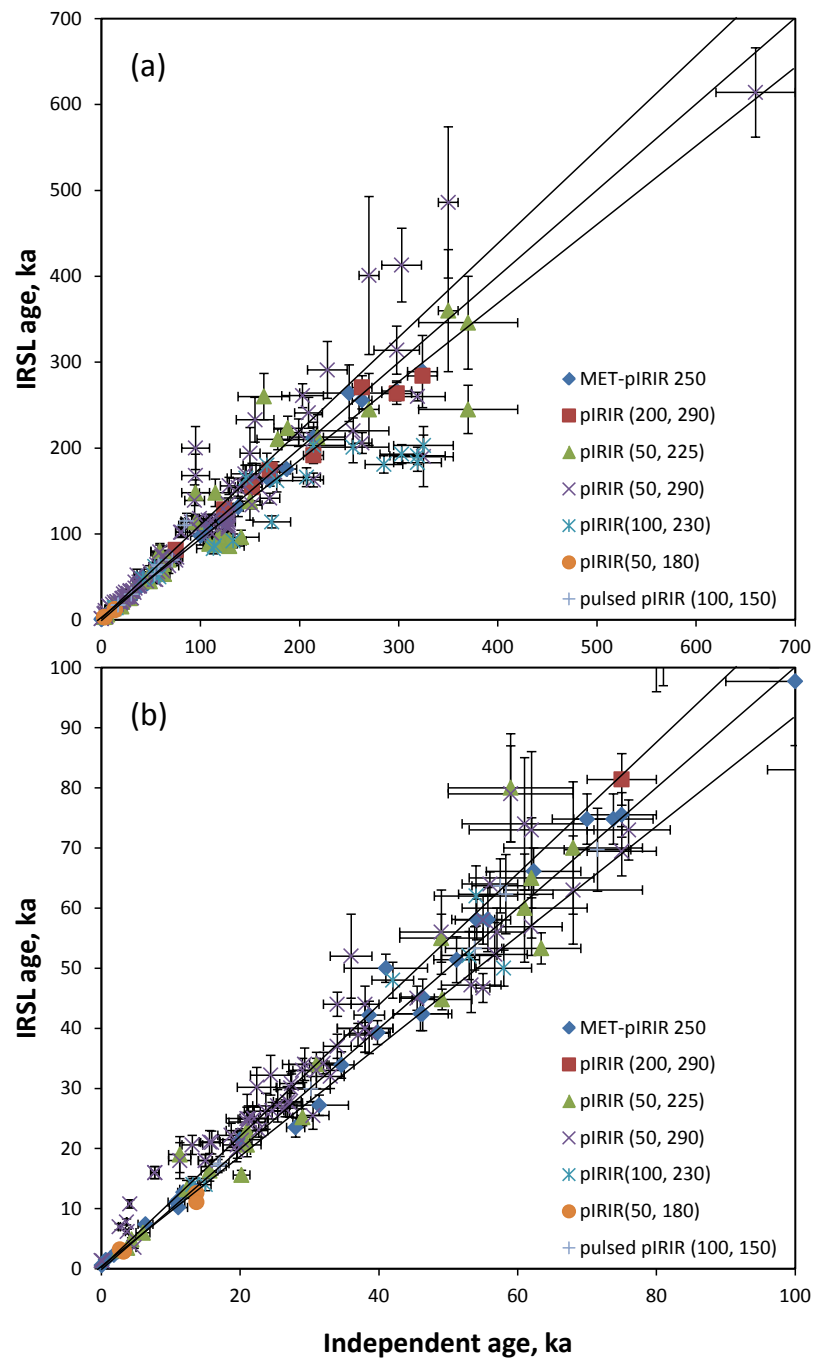

Fig. 10. (a) A summary of the feldspar pIRIR ages obtained using various pIRIR methods with comparison to the independent ages (see Table S1 for original data). (b) The data sets for samples younger than 100 ka only.

\section{SUMMARY}

The discovery of the fading-immune feature of the pIRIR signal and development of various pIRIR procedures has, for the first time, provided an effective way to overcome anomalous fading in feldspar. The pIRIR method does not only allow an extension of the age limit of luminescence dating, but also allow dating of sediments in which little quartz grains are found or that contain quartz grains with unwanted OSL behaviours. It, thus, opened up a new era of luminescence dating of sediments using feldspars. Although promising results have been reported by a number of published studies, important problems have been reported and remain unanswered: 
1) Many of the fading-uncorrected pIRIR ages agree with independent age control. This agreement, however, is inconsistent with the non-zero apparent laboratory fading rates. For ages that are either underestimated or overestimated, it is not clear whether this inconsistency is a result of the observed fading rate or the $D_{\mathrm{e}}$ estimate, or both, being an artefact.

2) A complex and variable SAR performance of the pIRIR signals has been observed for different samples from different regions. The choice of preheat temperature appears to be critical for some samples, but not for all. The dependence of IR stimulation temperatures, either prior-IR stimulation or pIRIR stimulation temperature, was also variable from sample to sample. The effect of thermal transfer and the size of test dose could also be a potential influence on $D_{\mathrm{e}}$ estimation. All these observations suggest that there is no universal pIRIR procedure applicable to every sample. One need to conduct comprehensive experimental tests to find the best suitable pIRIR procedures for any particular set of samples.

3) The residual dose appears to be highly variable from sample to sample and from region to region (Fig. 56). The source of the residual signal is still poorly understood, which may potentially affect the accuracy of age estimation. A modern analogue may provide an estimate on the true residual dose before burial, but this does not guarantee a reliable estimate of the true residual dose. At this point in time, most studies either do not deal with the residual dose or simply subtract a residual dose from the apparent $D_{\mathrm{e}}$ value with the residual inferred from measurement of fully bleached grains of the same or different samples. The dose dependence of the residual signal and the effect of thermal treatment (or thermal transfer) require further investigation, before it can be appropriately corrected for.

4) From the published data, it appears that the application of pIRIR dating methods is most successful for samples between 20 and $100 \mathrm{ka}$. However, it was less successful for older samples (e.g., >100 ka), where the pIRIR dating method is most useful compared to quartz OSL dating.

In summary, we reiterate previous suggestions that a preheat plateau test, residual signal measurements, a fading rate test, and dose recovery tests should be conducted as minimum criteria to validate the reliability of any pIRIR procedure. These tests, however, do not necessarily guarantee the accuracy of dating results, but can provide useful insights into the sensitivity of samples to different parameters of the method. Given the fact that the published studies are more likely to be dominant by successful application of pIRIR dating, and failed attempts of pIRIR dating is less likely to be published, the results summarised in this study is probably biased to successful applications and, therefore, should be regarded as an optimistic review. Finally, dating more sites, where independent age controls are available, is required.

\section{ACKNOWLEDGEMENTS}

The authors thank the two anonymous reviewers for their thorough reviews and constructive comments. We thank the organisation committee of the $3^{\text {rd }}$ APLED conference held at the University of Okayama, Japan, in 2012 for inviting us to present this review. Sally Lowick is appreciated for providing raw data from Lowick et al. (2012). This study was supported by a University of Wollongong Vice-Chancellor's Postdoctoral Research Fellowship to B Li, by Australian Research Council grants and fellowships to Roberts (DP0880675) and Jacobs (DP1092843), and by the Research Grant Council of the Hong Kong Special Administrative Region, China, to SHL (7033/12P).

\section{APPENDIX}

Two figures and two tables are available as Supplementary Material in electronic version of this article at http://dx.doi.org/10.2478/s13386-013-0160-3. Fig. S1: Solar simulator bleaching experiments for IRSL and pIRIR signals reported by (A) Buylaert et al. (2012) and (B) Li and Li (2011a). Fig. S2: Anomalous fading rates (g-values) for the MET-pIRIR signals of a sample (HLD3) from northeast China, plotted against stimulation temperature (data from $\mathrm{Li}$ and $\mathrm{Li}, 2011 \mathrm{a}$ ). Table S1: Summary of the pIRIR dating results from recently published studies using different pIRIR procedures. Table S2: Summary of the pIRIR dose recovery results from recently published and unpublished studies using different pIRIR procedures.

\section{REFERENCES}

Aitken MJ, 1985. Thermoluminescence dating. Academic press, London.

Aitken MJ, 1998. An Introduction to Optical Dating. Oxford University Press. London, $267 \mathrm{pp}$.

Alappat L, Tsukamoto S, Singh P, Srikanth D, Ramesh R and Frechen M, 2010. Chronology of Cauvery Delta Sediments from Shallow Subsurface Cores Using Elevated-Temperature Post-Ir Irsl Dating of Feldspar. Geochronometria 37: 37-47, DOI 10.2478/v10003010-0025-1.

Andersen MT, Jain M and Tidemand-Lichtenberg P, 2012. Red-IR stimulated luminescence in K-feldspar: Single or multiple trap origin? Journal of Applied Physics 112: 043507, DOI 10.1063/1.4745018.

Auclair M, Lamothe M and Huot S, 2003. Measurement of anomalous fading for feldspar IRSL using SAR. Radiation Measurements 37(4-5): 487-492, DOI 10.1016/S1350-4487(03)00018-0.

Baril MR and Huntley DJ, 2003. Infrared stimulated luminescence and phosphorescence spectra of irradiated feldspars. Journal of Physics: Condensed Matter 15(46): 8029-8048, DOI 10.1088/0953-8984/15/46/018.

Buylaert JP, Jain M, Murray AS, Thomsen KJ, Thiel C and Sohbati R, 2012. A robust feldspar luminescence dating method for Middle 
and Late Pleistocene sediments. Boreas 41(3): 435-451, DOI 10.1111/j.1502-3885.2012.00248.x.

Buylaert JP, Murray AS, Thomsen KJ and Jain M, 2009. Testing the potential of an elevated temperature IRSL signal from K-feldspar. Radiation Measurements 44(5-6): 560-565, DOI 10.1016/j.radmeas.2009.02.007.

Buylaert JP, Thiel C, Murray AS, Vandenberghe DAG, Yi SW and Lu HY, 2011. IRSL and post-IR IRSL residual doses recorded in modern dust samples from the Chinese Loess Plateau. Geochronometria 38(4): 432-440, DOI 10.2478/s13386-0110047-0.

Chen G, Murray AS and Li SH, 2001. Effect of heating on the quartz dose-response curve. Radiation Measurements 33(1): 59-63, DOI 10.1016/S1350-4487(00)00134-7.

Chen YW, Li SH and Li B, 2013. Residual doses and sensitivity change of post IR IRSL signals from potassium feldspar under different bleaching conditions. Geochronometria 40(4): 229-238, DOI 10.2478/s13386-013-0128-3.

Fu X, Li B and Li SH, 2012a. Testing a multi-step post-IR IRSL dating method using polymineral fine grains from Chinese loess. Quaternary Geochronology 10: $8-15, \quad$ DOI 10.1016/j.quageo.2011.12.004.

$\mathrm{Fu} \mathrm{X}$ and $\mathrm{Li} \mathrm{SH}, 2013$. A modified multi-elevated-temperature post-IR IRSL protocol for dating of Holocene sediments using K-feldspar. Quaternary Geochronology 17: 44-54, DOI 10.1016/j.quageo.2013.02.004

Fu X, Zhang JF and Zhou LP, 2012b. Comparison of the properties of various optically stimulated luminescence signals from potassium feldspar. Radiation Measurements 47(3): 210-218, DOI 10.1016/j.radmeas.2011.12.007.

Galbraith RF, Roberts RG, Laslett GM, Yoshida H and Olley JM, 1999. Optical dating of single and multiple grains of quartz from Jinmium rock shelter, northern Australia, part 1, Experimental design and statistical models. Archaeometry 41(2): 339-364, DOI 10.1111/j.1475-4754.1999.tb00987.x.

Galbraith RF and Roberts RG, 2012. Statistical aspects of equivalent dose and error calculation and display in OSL dating: an overview and some recommendations. Quaternary Geochronology 11: 1-27, DOI 10.1016/j.quageo.2012.04.020.

Gliganic LA, Jacobs Z, Roberts RG, Dominguez-Rodrigo M and Mabulla AZP, 2012. New ages for Middle and Later Stone Age deposits at Mumba rockshelter, Tanzania: Optically stimulated luminescence dating of quartz and feldspar grains. Journal of Human Evolution 62(4): 533-547, DOI 10.1016/j.jhevol.2012.02.004.

Guérin G and Valladas H, 1980. Thermoluminescene dating of volcanic plagioclases. Nature 286: 697-699, DOI 10.1038/286697a0.

Huntley DJ, 2011. Comment on "Isochron dating of sediments using luminescence of K-feldspar grains" by B. Li et al. Journal of Geophysical Research: Earth Surface 116(F1): F01012, DOI 10.1029/2010JF001856.

Huntley DJ and Lamothe M, 2001. Ubiquity of anomalous fading in Kfeldspars and the measurement and correction for it in optical dating. Canadian Journal of Earth Sciences 38(7): 1093-1106, DOI 10.1139/e01-013.

Huntley DJ and Lian OB, 2006. Some observations on tunnelling of trapped electrons in feldspars and their implications for optical dating. Quaternary Science Reviews 25(19-20): 2503-2512, DOI 10.1016/j.quascirev.2005.05.011.

Hütt G, Jaek I and Tchonka J, 1988. Optical dating: K-feldspars optical response stimulation spectra. Quaternary Science Reviews 7(3-4): 381-385, DOI 10.1016/0277-3791(88)90033-9.

Jain M and Ankjærgaard C, 2011. Towards a non-fading signal in feldspar: insight into charge transport and tunnelling from timeresolved optically stimulated luminescence. Radiation Measurements 46(3): $\quad 292-309, \quad$ DOI 10.1016/j.radmeas.2010.12.004.

Jain M and Singhvi AK, 2001. Limits to depletion of blue-green light stimulated luminescence in feldspars: implications for quartz dating. Radiation Measurements 33(6): 883-892, DOI 10.1016/S1350-4487(01)00104-4.
Kars RH, Busschers FS and Wallinga J, 2012. Validating post IR-IRSL dating on K-feldspars through comparison with quartz OSL ages. Quaternary Geochronology 12: 74-86, DOI 10.1016/j.quageo.2012.05.001.

Kars $\mathrm{RH}$, Wallinga $\mathrm{J}$ and Cohen KM, 2008. A new approach towards anomalous fading correction for feldspar IRSL dating - tests on samples in field saturation. Radiation Measurements 43(2-6): 786-790, DOI 10.1016/j.radmeas.2008.01.021.

Lamothe M and Auclair M, 1997. Assessing the datability of young sediments by IRSL using an intrinsic laboratory protocol. Radiation Measurements 27(2): 107-117, DOI 10.1016/S13504487(96)00140-0.

Lamothe M and Auclair M, 1999. A solution to anomalous fading and age shortfalls in optical dating of feldspar minerals. Earth and Planetary Science Letters 171(3): 319-323, DOI 10.1016/S0012821X(99)00180-6.

Lamothe M, Auclair M, Hamzaoui C and Huot S, 2003. Towards a prediction of long-term anomalous fading of feldspar IRSL. Radiation Measurements 37(4-5): 493-498, DOI 10.1016/S13504487(03)00016-7.

$\mathrm{Li} \mathrm{B}$ and $\mathrm{Li} \mathrm{SH}, 2008$. Investigations of the dose-dependent anomalous fading rate of feldspar from sediments. Journal of Physics DApplied Physics 41: 225502, DOI 10.1088/00223727/41/22/225502.

Li B and Li SH, 2011a. Luminescence dating of K-feldspar from sediments: A protocol without anomalous fading correction. Quaternary Geochronology 6(5): 468-479, DOI 10.1016/j.quageo.2011.05.001.

Li B and Li SH, 2011b. Thermal stability of infrared stimulated luminescence of sedimentary K-feldspar. Radiation Measurements 46(1): 29-36, DOI 10.1016/j.radmeas.2010.10.002.

$\mathrm{Li} \mathrm{B}$ and $\mathrm{Li} \mathrm{SH}, 2012 \mathrm{a}$. Luminescence dating of Chinese loess beyond $130 \mathrm{ka}$ using the non-fading signal from K-feldspar. Quaternary Geochronology 10: 24-31, DOI 10.1016/j.quageo.2011.12.005.

Li B and Li SH, 2012b. A reply to the comments by Thomsen et al. on "Luminescence dating of K-feldspar from sediments: A protocol without anomalous fading correction". Quaternary Geochronology 8: 49-51, DOI 10.1016/j.quageo.2011.10.001.

$\mathrm{Li} \mathrm{B}$ and $\mathrm{Li} \mathrm{SH}, 2013$. The effect of band-tail states on the thermal stability of the infrared stimulated luminescence from K-feldspar. Journal of Luminescence 136: 5-10, DOI 10.1016/j.jlumin.2012.08.043.

Li B, Li SH and Wintle AG, 2008a. Overcoming environmental dose rate changes in luminescence dating of waterlain deposits. Geochronometria 30: 33-40, DOI 10.2478/v10003-008-0003-z.

Li B, Li SH, Wintle AG and Zhao H, 2007a. Isochron measurements of naturally irradiated K-feldspar grains. Radiation Measurements 42(8): 1315-1327, DOI 10.1016/j.radmeas.2007.09.008.

Li B, Li SH, Wintle AG and Zhao H, 2008b. Isochron dating of sediments using luminescence of K-feldspar grains. Journal of Geophysical Research: Earth Surface 113(F2): F02026, DOI 10.1029/2007JF000900.

Li B, Li SH and Zhao H, 2011. Reply to comment by Huntley on "Isochron dating of sediments using luminescence of K-feldspar grains". Journal of Geophysical Research: Earth Surface 116(F1): F01013,.DOI 10.1029/2010JF001931.

Li B, Roberts RG and Jacobs Z, 2013. On the dose dependency of the bleachable and non-bleachable components of IRSL from Kfeldspar: improved procedures for the dating of Quaternary sediments. Quaternary Geochronology 17: 1-13, DOI 10.1016/j.quageo.2013.03.006.

Li SH, Chen YY, Li B, Sun JM and Yang LR, 2007b. OSL dating of sediments from desert in northern China. Quaternary Geochronology $2(1-4): \quad 23-28, \quad$ DOI 10.1016/j.quageo.2006.05.034.

Li SH and Tso MYW, 1997. Lifetime determination of OSL signals from potassium feldspar. Radiation Measurements 27(2): 119 121, DOI 10.1016/S1350-4487(96)00145-X.

Li SH, Tso MYW and Wong NWL, 1997. Parameters of OSL traps determined with various linear heating rates. Radiation 
Measurements 27(1): 43-47, DOI 10.1016/S1350-4487(96)001370.

Lowick SE, Trauerstein M and Preusser F, 2012. Testing the application of post IR-IRSL dating to fine grain waterlain sediments. Quaternary Geochronology 8: $33-40, \quad$ DOI 10.1016/j.quageo.2011.12.003.

Morthekai P, Jain M, Murray AS, Thomsen KJ and Bøtter-Jensen L, 2008. Fading characteristics of martian analogue materials and the applicability of a correction procedure. Radiation Measurements 43(2-6): 672-678, DOI 10.1016/j.radmeas.2008.02.019.

Murray AS, Buylaert JP, Thomsen KJ and Jain M, 2009. The effect of preheating on the IRSL signal from feldspar. Radiation

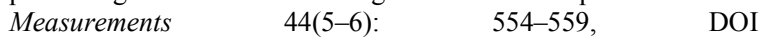
10.1016/j.radmeas.2009.02.004.

Murray AS and Roberts RG, 1998. Measurement of the equivalent dose in quartz using a regenerative-dose single-aliquot protocol. Radiation Measurements 29(5): 503-515, DOI 10.1016/S13504487(98)00044-4.

Murray AS, Thomsen KJ, Masuda N, Buylaert JP and Jain M, 2012. Identifying well-bleached quartz using the different bleaching rates of quartz and feldspar luminescence signals. Radiation Measurements $\quad 47(9): \quad 688-695, \quad$ DOI 10.1016/j.radmeas.2012.05.006.

Murray AS and Wintle AG, 2000. Luminescence dating of quartz using an improved single-aliquot regenerative-dose protocol. Radiation Measurements 32(1): 57-73, DOI 10.1016/S1350-4487(99)00253$\mathrm{X}$.

Poolton NRJ, Kars RH, Wallinga J and Bos AJJ, 2009. Direct evidence for the participation of band-tails and excited-state tunnelling in the luminescence of irradiated feldspars. Journal of Physics: Condensed Matter 21: 485505, DOI 10.1088/09538984/21/48/485505.

Poolton NRJ, Ozanyan KB, Wallinga J, Murray AS and Bøtter-Jensen L, 2002. Electrons in feldspar II: a consideration of the influence of conduction band-tail states on luminescence processes. Physics and Chemistry of Minerals 29(3): 217-225, DOI 10.1007/s00269001-0218-2.

Qin JT and Zhou LP, 2012. Effects of thermally transferred signals in the post-IR IRSL SAR protocol. Radiation Measurements 47(9): 710-715, DOI 10.1016/j.radmeas.2011.12.011.

Ramos AM, Cunha PP, Cunha LS, Gomes A, Lopes FC, Buylaert JP and Murray AS, 2012. The River Mondego terraces at the Figueira da Foz coastal area (western central Portugal): Geomorphological and sedimentological characterization of a terrace staircase affected by differential uplift and glacio-eustasy. Geomorphology 165-166: 107-123, DOI 10.1016/j.geomorph.2012.03.037.

Reimann T and Tsukamoto S, 2012. Dating the recent past ( $<500$ years) by post-IR IRSL feldspar - Examples from the North Sea and Baltic Sea coast. Quaternary Geochronology 10: 180-187, DOI 10.1016/j.quageo.2012.04.011.

Reimann T, Tsukamoto S, Naumann M and Frechen M, 2011. The potential of using K-rich feldspars for optical dating of young coastal sediments - A test case from Darss-Zingst peninsula (southern Baltic Sea coast). Quaternary Geochronology 6(2): 207222, DOI 10.1016/j.quageo.2010.10.001.

Roberts HM, 2012. Testing Post-IR IRSL protocols for minimising fading in feldspars, using Alaskan loess with independent chronological control. Radiation Measurements 47(9): 716-724, DOI 10.1016/j.radmeas.2012.03.022.

Roberts RG, Galbraith RF, Olley JM, Yoshida H and Laslett GM, 1999. Optical dating of single and multiple grains of quartz from jinmium rock shelter, northern Australia, part 2, Results and implications. Archaeometry 41(2): 365-395, DOI 10.1111/j.14754754.1999.tb00988.x.

Roskosch J, Tsukamoto S, Meinsen J, Frechen M and Winsemann J, 2012. Luminescence dating of an Upper Pleistocene alluvial fan and aeolian sandsheet complex: The Senne in the Munsterland Embayment, NW Germany. Quaternary Geochronology 10: 94101, DOI 10.1016/j.quageo.2012.02.012.
Sanderson DCW and Clark RJ, 1994. Pulsed photostimulated luminescence of alkali feldspars. Radiation Measurements 23(23): 633-639, DOI 10.1016/1350-4487(94)90112-0.

Schatz AK, Buylaert JP, Murray A, Stevens T and Scholten T, 2012. Establishing a luminescence chronology for a palaeosol-loess profile at Tokaj (Hungary): A comparison of quartz OSL and polymineral IRSL signals. Quaternary Geochronology 10: 68-74, DOI 10.1016/j.quageo.2012.02.018.

Schmidt ED, Frechen M, Murray AS, Tsukamoto S and Bittmann F, 2011. Luminescence chronology of the loess record from the Tonchesberg section: A comparison of using quartz and feldspar as dosimeter to extend the age range beyond the Eemian. Quaternary International 234(1-2): 10-22, DOI 10.1016/j.quaint.2010.07.012.

Sohbati R, Murray AS, Buylaert JP, Ortuno M, Cunha PP and Masana E, 2012. Luminescence dating of Pleistocene alluvial sediments affected by the Alhama de Murcia fault (eastern Betics, Spain) - a comparison between OSL, IRSL and post-IR IRSL ages. Boreas 41(2): 250-262, DOI 10.1111/j.1502-3885.2011.00230.x.

Spooner NA, 1992. Optical Dating: Preliminary-Results on the Anomalous Fading of Luminescence from Feldspars. Quaternary Science Reviews 11(1-2): 139-145, DOI 10.1016/02773791(92)90055-D.

Spooner NA, 1994. The anomalous fading of infrared-stimulated luminescence from feldspars. Radiation Measurements 23(2-3): 625-632, DOI 10.1016/1350-4487(94)90111-2.

Stevens T, Markovic SB, Zech M, Hambach U and Sumegi P, 2011. Dust deposition and climate in the Carpathian Basin over an independently dated last glacial-interglacial cycle. Quaternary Science Reviews 30(5-6): 662-681, DOI 10.1016/j.quascirev.2010.12.011.

Templer RH, 1985. The Removal of Anomalous Fading in Zircon. Nuclear Tracks and Radiation Measurements 10(4-6): 531-537, DOI 10.1016/0735-245X(85)90054-7.

Thiel C, Buylaert JP, Murray A, Terhorst B, Hofer I, Tsukamoto S and Frechen M, 2011a. Luminescence dating of the Stratzing loess profile (Austria) - testing the potential of an elevated temperature post-IR IRSL protocol. Quaternary International 234(1-2): 23-31, DOI 10.1016/j.quaint.2010.05.018.

Thiel C, Buylaert JP, Murray AS, Elmejdoub N and Jedoui Y, 2012. A comparison of TT-OSL and post-IR IRSL dating of coastal deposits on Cap Bon peninsula, north-eastern Tunisia. Quaternary Geochronology 10: 209-217, DOI 10.1016/j.quageo.2012.03.010.

Thiel C, Buylaert JP, Murray AS and Tsukamoto S, 2011b. On the applicability of post-IR IRSL dating to Japanese loess. Geochronometria 38(4): 369-378, DOI 10.2478/s13386-0110043-4.

Thiel C, Buylaert J-P, Murray AS, Terhorst B, Tsukamoto S, Frechen M and Sprafke T, 2011c. Investigating the chronostratigraphy of prominent palaeosols in Lower Austria using post-IR IRSL dating. Quaternary Science Journal 60(1): 137-152, DOI 10.3285/eg.60.1.10.

Thiel C, Terhorst B, Jaburová I, Buylaert J-P, Murray AS, Fladerer FA, Damm B, Frechen M and Ottner F, 2011d. Sedimentation and erosion processes in Middle to Late Pleistocene sequences exposed in the brickyard of Langenlois/Lower Austria. Geomorphology 135(3-4): 295-307, DOI 10.1016/j.geomorph.2011.02.011.

Thomsen KJ, Murray AS and Jain M, 2011. Stability of IRSL signals from sedimentary K-feldspar samples. Geochronometria 38(1): 113, DOI 10.2478/s13386-011-0003-z.

Thomsen KJ, Murray AS, Jain M and Botter-Jensen L, 2008. Laboratory fading rates of various luminescence signals from feldspar-rich sediment extracts. Radiation Measurements 43(910): 1474-1486, DOI 10.1016/j.radmeas.2008.06.002.

Thomsen KJ, Murray AS, Jain M and Buylaert JP, 2012. Re 'Luminescence dating of K-feldspar from sediments: a protocol without anomalous fading correction' by Bo Li and Sheng-Hua Li. Quaternary Geochronology 8: 46-48, DOI 10.1016/j.quageo.2011.07.002.

Tsukamoto S, Denby PM, Murray AS and Botter-Jensen L, 2006. Timeresolved luminescence from feldspars: New insight into fading. 
Radiation Measurements 41(7-8): 790-795, DOI 10.1016/j.radmeas.2006.05.013.

Valladas G and Valladas H, 1979. High temperature thermoluminescence. Proceedings of the $18^{\text {th }}$ International Symposium on Archaeometry and Archaeological Prospection, Bonn: 506-510.

Vasiliniuc S, Vandenberghe DAG, Timar-Gabor A, Panaiotu C, Cosma C and van den Haute P, 2012. Testing the potential of elevated temperature post-IR IRSL signals for dating Romanian loess. Quaternary Geochronology 10: $75-80, \quad$ DOI 10.1016/j.quageo.2012.02.014.

Visocekas R, 1985. Tunneling radiative recombination in labradorite: its association with anomalous fading of thermoluminescence. Nuclear Tracks and Radiation Measurements 10(4-6): 521-529, DOI 10.1016/0735-245X(85)90053-5.

Visocekas R, Spooner NA, Zink A and Blanc P, 1994. Tunnel afterglow, fading and infrared-emission in thermoluminescence of feldspars. Radiation Measurements 23(2-3): 377-385, DOI 10(46): 521-529, DOI 10.1016/0735-245X(85)90053-5.

Wacha L and Frechen M, 2011. The geochronology of the "Gorjanovic loess section" in Vukovar, Croatia. Quaternary International 240(1-2): 87-99, DOI 10.1016/j.quaint.2011.04.010.
Wallinga J, Murray A and Wintle A, 2000. The single-aliquot regenerative-dose (SAR) protocol applied to coarse-grain feldspar. Radiation Measurements 32(5-6): 529-533, DOI 10.1016/S13504487(00)00091-3.

Wang XL and Wintle AG, 2013. Investigating the contribution of recuperated TL to post-IR IRSL signals in a perthitic feldspar. Radiation Measurements 49: $82-87, \quad$ DOI 10.1016/j.radmeas.2012.12.003.

Watanuki T, Murray AS and Tsukamoto S, 2005. Quartz and polymineral luminescence dating of Japanese loess over the last 0.6 Ma: Comparison with an independent chronology. Earth and Planetary Science Letters 240(3-4): 774-789, DOI 10.1016/j.eps1.2005.09.027.

Wintle AG, 1973. Anomalous fading of thermoluminescence in mineral samples. Nature 245: 143-144, DOI 10.1038/245143a0.

Wintle AG and Murray AS, 2006. A review of quartz optically stimulated luminescence characteristics and their relevance in single-aliquot regeneration dating protocols. Radiation Measurements $\quad 41(4): \quad 369-391, \quad$ DOI 10.1016/j.radmeas.2005.11.001.

Zhao $\mathrm{H}$ and $\mathrm{Li} \mathrm{SH}, 2002$. Luminescence isochron dating: a new approach using different grain sizes. Radiation Protection Dosimetry 101: 333-338. 